\title{
Entropy Generation/Availability Energy Loss Analysis Inside MIT Gas Spring and "Two-Space" Test Rigs
}

Asuquo B. Ebiana, Rupesh T. Savadekar, and Kaushal V. Patel

Cleveland State University, Cleveland, Ohio 


\section{NASA STI Program . . . in Profile}

Since its founding, NASA has been dedicated to the advancement of aeronautics and space science. The NASA Scientific and Technical Information (STI) program plays a key part in helping NASA maintain this important role.

The NASA STI Program operates under the auspices of the Agency Chief Information Officer. It collects, organizes, provides for archiving, and disseminates NASA's STI. The NASA STI program provides access to the NASA Aeronautics and Space Database and its public interface, the NASA Technical Reports Server, thus providing one of the largest collections of aeronautical and space science STI in the world. Results are published in both non-NASA channels and by NASA in the NASA STI Report Series, which includes the following report types:

- TECHNICAL PUBLICATION. Reports of completed research or a major significant phase of research that present the results of NASA programs and include extensive data or theoretical analysis. Includes compilations of significant scientific and technical data and information deemed to be of continuing reference value. NASA counterpart of peer-reviewed formal professional papers but has less stringent limitations on manuscript length and extent of graphic presentations.

- TECHNICAL MEMORANDUM. Scientific and technical findings that are preliminary or of specialized interest, e.g., quick release reports, working papers, and bibliographies that contain minimal annotation. Does not contain extensive analysis.

- CONTRACTOR REPORT. Scientific and technical findings by NASA-sponsored contractors and grantees.
- CONFERENCE PUBLICATION. Collected papers from scientific and technical conferences, symposia, seminars, or other meetings sponsored or cosponsored by NASA.

- SPECIAL PUBLICATION. Scientific, technical, or historical information from NASA programs, projects, and missions, often concerned with subjects having substantial public interest.

- TECHNICAL TRANSLATION. Englishlanguage translations of foreign scientific and technical material pertinent to NASA's mission.

Specialized services also include creating custom thesauri, building customized databases, organizing and publishing research results.

For more information about the NASA STI program, see the following:

- Access the NASA STI program home page at http://www.sti.nasa.gov

- E-mail your question via the Internet to help@sti.nasa.gov

- Fax your question to the NASA STI Help Desk at 301-621-0134

- Telephone the NASA STI Help Desk at 301-621-0390

- Write to:

NASA STI Help Desk

NASA Center for AeroSpace Information 7121 Standard Drive Hanover, MD 21076-1320 


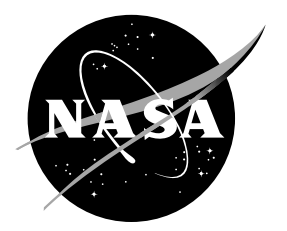

\section{Entropy Generation/Availability Energy Loss Analysis Inside MIT Gas Spring and "Two-Space" Test Rigs}

Asuquo B. Ebiana, Rupesh T. Savadekar, and Kaushal V. Patel

Cleveland State University, Cleveland, Ohio

Prepared for the

Third International Energy Conversion Engineering Conference (IECEC)

sponsored by the American Institute of Aeronautics and Astronautics

San Francisco, California, August 15-18, 2005

Prepared under Grant NAG3-2819

National Aeronautics and

Space Administration

Glenn Research Center

Cleveland, Ohio 44135 


\section{Acknowledgments}

The work described in this paper was performed for the Science Mission Directorate (SMD) and the Radioisotope Power System (RPS) Program which provided the National Aeronautics and Space Administration (NASA) funding for this grant. We are grateful for the sponsorship of this contract by the NASA Glenn Research Center under grant NAG3-2819. The contract monitor is Roy Tew, Jr. We wish to acknowledge the valuable and insightful guidance we received from him and the generous disposition of his time throughout the duration of this study.

Trade names and trademarks are used in this report for identification only. Their usage does not constitute an official endorsement, either expressed or implied, by the National Aeronautics and Space Administration.

Level of Review: This material has been technically reviewed by NASA technical management

Available from

NASA Center for Aerospace Information 7121 Standard Drive

Hanover, MD 21076-1320
National Technical Information Service 5285 Port Royal Road Springfield, VA 22161 


\title{
Entropy Generation/Availability Energy Loss Analysis Inside MIT Gas Spring and "Two-Space" Test Rigs
}

\author{
Asuquo B. Ebiana, Rupesh T. Salvadekar, and Kaushal V. Patel \\ Cleveland State University \\ Cleveland, Ohio 44115
}

\begin{abstract}
The results of the entropy generation and availability energy loss analysis under conditions of oscillating pressure and oscillating helium gas flow in two Massachusetts Institute of Technology (MIT) test rigs - pistoncylinder and piston-cylinder-heat exchanger - are presented. Two solution domains, the gas spring ("single-space") in the piston-cylinder test rig and the gas spring + heat exchanger ("two-space") in the piston-cylinder-heat exchanger test rig are of interest. Sage and CFD-ACE+ commercial numerical codes are used to obtain 1-D and 2-D computer models, respectively, of each of the two solution domains and to simulate the oscillating gas flow and heat transfer effects in these domains. Second law analysis is used to characterize the entropy generation and availability energy losses inside the two solution domains. Internal and external entropy generation and availability energy loss results predicted by Sage and CFD-ACE+ are compared. Thermodynamic loss analysis of simple systems such as the MIT test rigs are often useful to understand some important features of complex pattern forming processes in more complex systems like the Stirling engine. This study is aimed at improving numerical codes for the prediction of thermodynamic losses via the development of a loss post-processor. The incorporation of loss post-processors in Stirling engine numerical codes will facilitate Stirling engine performance optimization. Loss analysis using entropy-generation rates due to heat and fluid flow is a relatively new technique for assessing component performance. It offers a deep insight into the flow phenomena, allows a more exact calculation of losses than is possible with traditional means involving the application of loss correlations and provides an effective tool for improving component and overall system performance.
\end{abstract}

\section{Latin letters}

A Control surface

AE Available energy

AEfric AE(due to friction)

$A E Q_{w} \quad A E$ (due to surface heat flow)

$\mathrm{AEQ}_{\mathrm{x}} \quad \mathrm{AE}$ (axial heat flow)

AEDiscr Discrepancy ( $\mathrm{AE}_{\text {int }}$ vs. $\mathrm{AE}_{\mathrm{ext}}$ )

$C_{p} \quad$ Specific heat at const. pressure

$\mathrm{C}_{\mathrm{v}} \quad$ Specific heat at const. volume

D Cylinder bore (diameter) ( $\mathrm{mm}$ )

E Total energy

h Enthalpy

$\mathrm{k} \quad$ Thermal conductivity

ke Kinetic energy

M Total mass; Number of inlets

$\dot{\mathrm{m}}$ Mass flow rate

N Number of outlets

n Unit normal vector

P Pressure

pe Potential energy

Q Heat transfer

q Heat flux vector

$\mathrm{R}$ Gas constant

$\mathrm{r}_{\mathrm{v}} \quad$ Volume ratio

S Piston stroke; Total enthalpy

$\mathrm{S}_{\text {gen }} \quad$ Entropy generation

$\mathrm{s}_{\text {gen }}^{\prime \prime \prime} \quad$ Volumetric entropy generation

\section{Nomenclature}

$\begin{array}{ll}\mathrm{s} & \text { Mass specific entropy } \\ \mathrm{T} & \text { Temperature } \\ \# \text { tspc } & \text { Number of time steps per cycle } \\ \mathrm{t} & \text { Time (sec.) } \\ \Delta \mathrm{t} & \text { Time step (sec.) } \\ \mathrm{u} & \text { Internal energy } \\ \mathrm{V} & \text { Control volume } \\ \mathrm{v} & \text { Mass specific volume } \\ \mathrm{W} & \text { Work } \\ \mathrm{x}, \mathrm{y}, \mathrm{z} & \text { Cartesian coordinates } \\ \mathrm{X}_{\mathrm{i}} & \text { Mass fraction }\end{array}$

\section{Greek letters}

$\nabla \quad$ Gradient

$\Delta \quad$ Change

$\eta \quad$ Efficiency

$\mu \quad$ Dynamic viscosity

$\Phi$ Dissipation function

$\rho \quad$ Fluid density

$\theta \quad$ Crank angle

$\begin{array}{ll}\text { Subscripts } \\ \text { cond } & \text { Conductive } \\ \text { e } & \text { Exit } \\ \text { gen } & \text { Generation }\end{array}$

$\begin{array}{ll}\mathrm{H} & \text { High } \\ \mathrm{i} & \text { Inlet; Index; Irreversible } \\ \text { int } & \text { Internal } \\ \mathrm{L} & \text { Low } \\ \text { mix } & \text { Mixing } \\ \mathrm{o} & \text { Outflow } \\ \mathrm{p} & \text { Pressure } \\ \mathrm{r} & \text { Region, Reversible } \\ \text { rev } & \text { Reversible } \\ \text { th } & \text { Thermal } \\ \mathrm{v} & \text { Volume } \\ \text { visc } & \text { Viscous }\end{array}$

$\begin{array}{ll}\text { Abbreviations } \\ \text { BDC } & \text { Bottom Dead Center } \\ \text { CFD } & \text { Computational Fluid Dynamics } \\ \text { DTF } & \text { Database Template File } \\ \text { GRC } & \text { Glenn Research Center } \\ \text { MIT } & \text { Mass. Institute of Technology } \\ \text { NASA } & \text { Natl. Aero.\& Space Admin. } \\ \text { n-D } & (\mathrm{n}=1,2,3) \text { Dimension } \\ \text { RMS } & \text { Root Mean Square } \\ \text { SRG } & \text { Stirling Radioisotope Generator } \\ \text { TDC } & \text { Top Dead Center } \\ \text { TFE } & \text { Teflon }\end{array}$




\section{Introduction}

\section{A. Background}

Under the auspices of NASA's nuclear systems program, the Department of Energy, Lockheed Martin Corporation of Valley Forge, PA, INFINIA Corp. (formerly Stirling Technology Company, Inc.) of Kennewick, WA and NASA Glenn Research Center are developing a high-efficiency Stirling Radioisotope Generator (SRG) for possible use on future NASA Space Science Missions. The SRG is being developed for multi-mission use (e.g., in environments with and without atmospheres), including providing electric power for unmanned Mars rovers and deep space missions. Performance and mass improvement goals have been established for second- and thirdgeneration Stirling radioisotope power systems. Multiple efforts are underway to achieve these goals, both in-house at GRC and under various grants and contracts. These efforts include development of a multi-dimensional Stirling computational fluid dynamics code, including second law analysis post-processing to separate various thermodynamic losses; high-temperature materials; advanced controllers; an end-to-end system dynamics model; low-vibration techniques; advanced regenerators; and a lightweight converter ${ }^{33}$.

This paper reports the results of a second law analysis post-processing effort to evaluate various thermodynamic losses in the flow spaces in two Massachusetts Institute of Technology (MIT) test rigs - piston-cylinder and pistoncylinder-heat exchanger - operating under conditions of oscillating pressure and oscillating flow. Extensive numerical analyses of the surface heat transfer, pressure, flow and temperature variations and hysteresis loss in the flow spaces have been undertaken in our earlier study ${ }^{13}$ and the results were shown to exhibit good qualitative similarities with some disagreement in magnitudes when compared with relevant experimental data and numerical results from the literature $e^{20,25,31}$. These numerical results are post processed for thermodynamic losses in this study.

Heat transfer effects in the presence of oscillating pressure and oscillating flow conditions are known to be important but poorly understood in a wide array of technically important mechanical power systems, such as gas compressors, automotive engines and Stirling engines to mention a few. A major design objective for these reciprocating engines is to achieve good heat transfer to and from the working fluid. Until recently the heat transfer estimates used in these equipment have been based on extrapolation of expressions that were developed for steadypressure, steady-flow conditions. Because the ordinary, steady-state convective model contains no term to account for the oscillatory effect in variable volumes, designs of these equipment are nowhere near optimum. Using the two MIT test rigs Kornhause ${ }^{20}$ confirmed experimentally that there was a fundamental difference between steady and oscillatory flow heat transfer in the variable cylinder volumes of the MIT test rigs. Building on the work done by Smith, Lee, Faulkner, and Chafe ${ }^{8,15,21}$, Kornhauser started the development of expressions suitable for oscillating pressure and oscillating flow conditions. He closely integrated experiment with analysis to achieve useful results with good qualitative but limited quantitative success.

During the heat to useful work conversion process in reciprocating heat engines, various thermodynamic loss mechanisms (pressure drop, finite heat transfer, friction, mixing, leakages, etc.), due to the non-ideal nature of the device, influence engine thermodynamic performance. Thus another design objective for reciprocating engines is to keep thermodynamic losses low. This objective however conflicts with the heat transfer objective because, for example, heat exchangers with higher heat transfer effectiveness generally have higher flow $\operatorname{losses}^{30}$. It is therefore valuable for the designer to know the trade-off between thermodynamic losses and heat transfer.

The second law of thermodynamics has proven to be a useful tool in identifying the mechanisms and system components that are responsible for thermodynamic losses and for indicating how to minimize these losses in practical equipment in order to improve performance. Five main approaches, developed over the last several decades and reported in the literature, form the basis of second-law analysis. These are, in order of decreasing comprehensiveness, exergy, physical-exergy, exergy-consumption, negentropy and entropy analyses. These second law analysis types can be grouped into two broad categories. The first (exergy and physical-exergy analyses) is more detailed, and examines systems in an analogous way to energy analysis. The second (exergy-consumption, negentropy and entropy analyses) is concerned mainly with losses due to internal irreversibilities. Exergy analysis is a thermodynamic approach used for analyzing and improving the efficiency of chemical and thermal processes. In the analysis and design of energy systems, techniques are often used which combine scientific disciplines (mainly thermodynamics) with economic disciplines (mainly cost accounting) to achieve optimum designs. Many researchers ${ }^{14,26,35,36}$ have developed methods of performing economic analysis based on exergy, which are referred to by such names as thermo-economics, second-law costing and exergo-economics. The potential usefulness of exergy in addressing and solving environment problems have also been demonstrated by several researchers ${ }^{6,7,9,19,27,38}$. An understanding of the relations between exergy and the environment may reveal the underlying fundamental patterns and forces affecting changes in the environment, and help researchers to deal better with environmental damage. Physical exergy includes all components of exergy except chemical exergy. Thus physical-exergy analysis may be 
sufficient if chemical exergy is not important to the analysis or if the process involves only fixed composition flow (e.g. steam power cycles). Physical-exergy cannot be rationally applied to processes in which compositions of streams change (e.g. combustion). Exergy consumption is the difference in exergy between input and output plus accumulations (if any) of general work potential for a system. Entropy generation destroys the available work of a system and is associated with irreversibilities related to three fluid dynamic processe ${ }^{11}$ : heat transfer across a nonzero temperature difference, viscous friction leading to pressure drop and non-equilibrium processes such as mixing of different streams of fluid, unrestrained expansion, non-quasi equilibrium compression and expansion, chemical reaction, leakages and other nonidealities within systems. The main difference between entropy and negentropy analyse ${ }^{18}$ is that negentropy is regarded as a valuable commodity while entropy is not. Except for entropy analysis, all other main second-law analyses adopt the negentropy viewpoint. The entropy analysis concept is employed in this study.

A valuable tool in the design of a high performance engine is a numerical code which can closely simulate the heat transfer, fluid dynamic and thermodynamic processes inside the engine and can account for all the thermodynamic losses. Sage and CFD-ACE+ commercial numerical codes are employed for this numerical study. The Sage code is a 1-D, multi-variable thermodynamic modeling package that supports simulation and optimization of spring-mass-damper resonant systems and Stirling-cycle coolers and engines. The CFD-ACE+ is an unstructured polyhedral cell flow solver for 2-D and 3-D problems. It provides an integrated grid generation module (CFDGEOM), a graphical user interface for preparation of the model (CFD-GUI), a computational solver for performing the simulation (CFD-ACE), and an interactive visualization program for examination and analysis of the simulation results (CFD-VIEW). It is integrated with a wide variety of other physics modules making it the core of a multidimensional, multi-disciplinary analysis environment.

\section{B. Scope/Objective}

This research effort can be broadly classified as:

- Modeling of the MIT Test Rigs

- Second Law Analysis via Entropy Generation

- Second Law Analysis Post Processing of Numerical Simulation Results

The Sage and CFD-ACE+ commercial numerical codes are employed to obtain 1-D and 2-D computer models, respectively, of each of the two solution domains of interest in Kornhauser's MIT test rigs - the gas spring ("singlespace") in the piston-cylinder test rig and the gas spring + heat exchanger ("two-space") in the piston-cylinder-heat exchanger test rig. Hereafter, gas spring and "single-space" will be used interchangeably; so also will gas spring + heat exchanger and "two-space".

Second law analyses focusing on entropy generation and its minimization have been playing a dominant role in recent times to understand the irreversibility in applied engineering and transport processes ${ }^{2,3,12}$. Bejan ${ }^{1}$ and Gedeon ${ }^{16}$ have focused on the different mechanisms behind entropy generation in applied thermal engineering. Numerous other investigations (mostly numerical) ${ }^{23,24,28}$ have been performed to determine the entropy generation and irreversibility profiles for different geometric configurations, flow situations, and thermal boundary conditions.

Sage and CFD-ACE+ simulation results of temperature, velocity, pressure and surface heat transfer were postprocessed for major thermodynamic losses using entropy generation analysis. An important and primary objective of this study is the development and application of a thermodynamic loss post-processor to characterize the major thermodynamic losses inside the two MIT test rigs. The experience gained from thermodynamic loss analysis of simple systems such as the MIT test rigs are often useful for application to more complex systems like the Stirling engine. Thus this study is motivated by the future need to incorporate a thermodynamic loss post-processor in Stirling engine analysis codes in order to facilitate the improvement of engine thermodynamic performance through better understanding of the heat transfer and power losses ${ }^{32}$.

\section{Modeling of MIT Test Rigs}

\section{A. MIT "Single Space" (Gas Spring) Test Rig}

Figure 1(a) shows a schematic representation of Kornhauser's piston-cylinder test rig. The test section consists of a closed piston-cylinder device mounted on a compressor base. The gas spring is the volume of gas confined by the fixed cylinder and the moving piston. The adjustable cylinder head enables different volume ratios to be achieved. A volume ratio is defined to be the maximum cylinder volume (piston at "bottom-dead-center" (BDC)) over the minimum cylinder volume (piston at "top-dead-center" (TDC)). A piston stroke length of $76.2 \mathrm{~mm}$ (3.00 in.) and volume ratio of 2.0 are used in this study. The compressor piston drives the piston in the $50.8 \mathrm{~mm}$ ( $2.00 \mathrm{in}$.) 


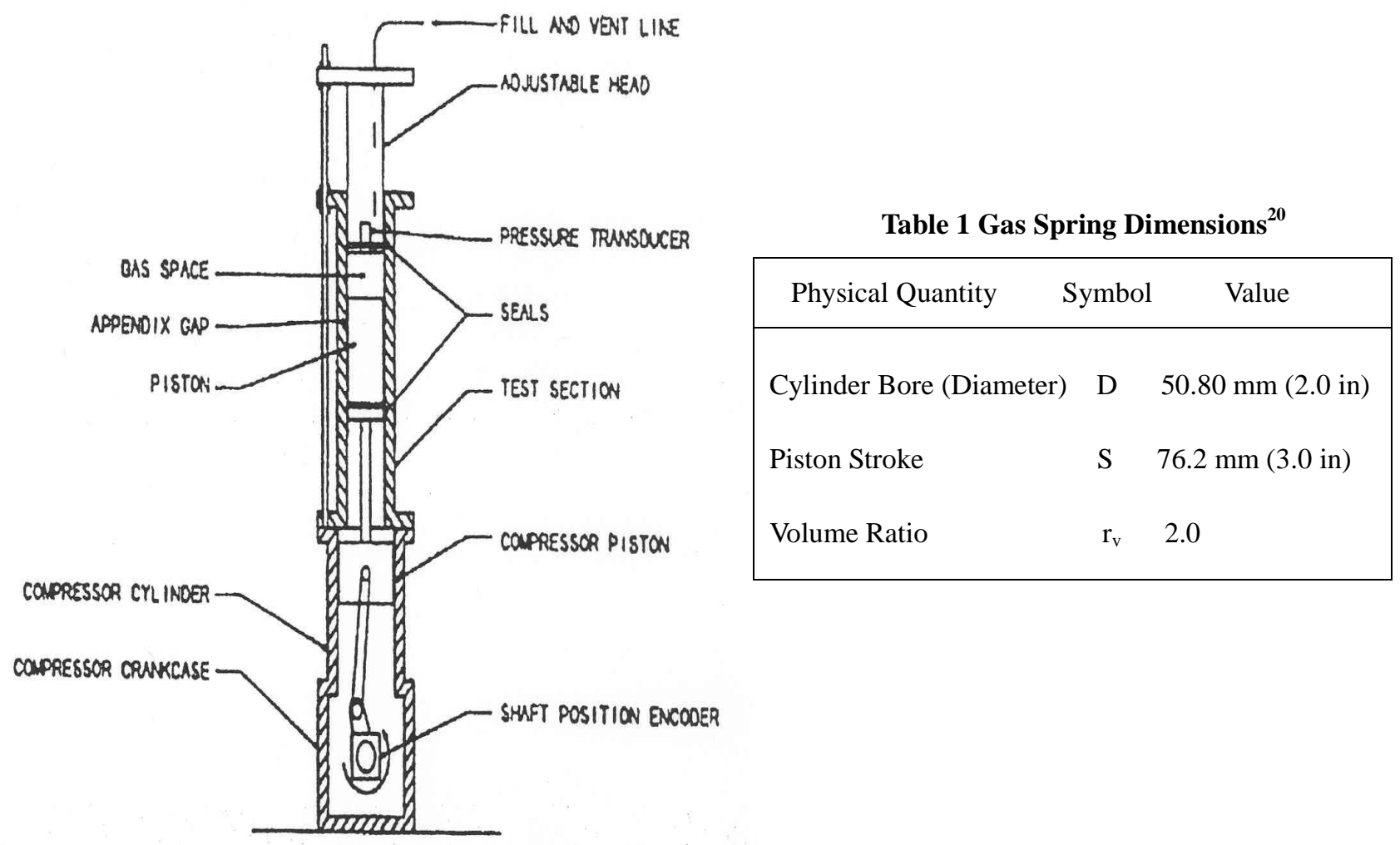

Figure 1(a). Kornhauser's MIT Piston-Cylinder Test Rig.

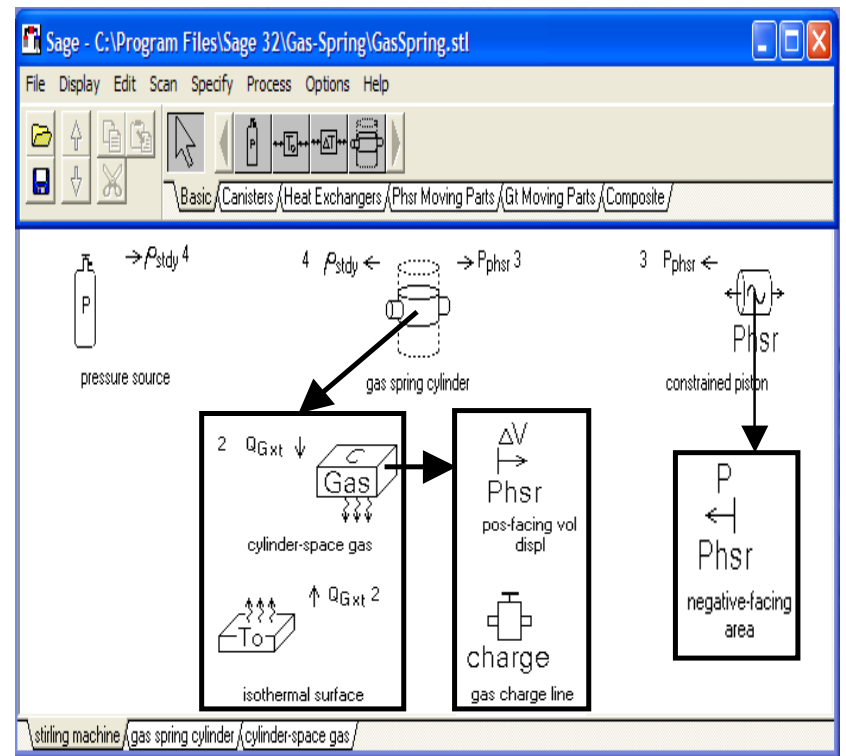

Figure 1(b). Sage Model (1-D) of Kornhauser's MIT Gas Spring.

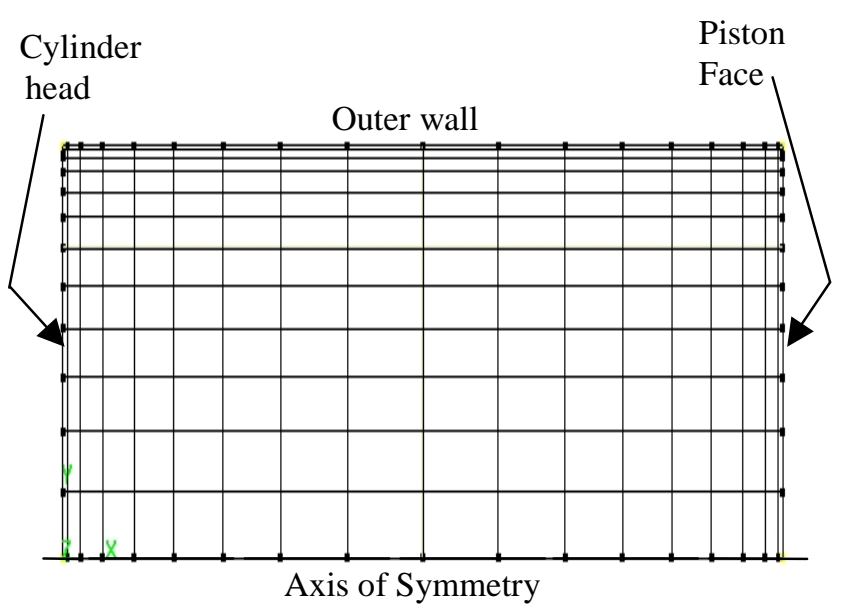

Figure 1(c). CFD-ACE+ 2-D Model of Kornhauser's MIT Gas Spring (Base Line Grid Size: 19 x 13). 
diameter cylinder. The piston is sealed to the cylinder with a buna-n O-ring located more than a stroke's length from the piston face so that frictional heating of the cylinder wall would only affect results minimally. The piston top surface is brass, while the cylinder wall and head are made of steel. The apparatus is belt driven by a D.C. motor to allow speed adjustment. The apparatus fill line is a capillary tube of negligible volume. The gas spring dimensions are tabulated in Table 1. Model representations of Kornhauser's closed piston-cylinder gas spring using Sage and CFD-ACE+ are illustrated in Figs. 1(b) and 1(c) respectively and discussed below.

\section{Sage Gas Spring Model (1-D)}

Figure 1(b) is a representation of the Sage graphical interface illustrating the 1-D model of Kornhauser's MIT gas spring. Sage provides 8 menus - File, Display, Edit, Scan, Specify, Process, Options, and Help - each with selfexplanatory commands and graphical edit windows with model-component palettes. When "show window" in the edit menu is activated, the highest level graphical edit window (Stirling machine window) and its model-component palette appear. Each model-component palette contains buttons arranged in tab-selected pages corresponding to different categories of model components. Figure 1(b) shows the Stirling machine window with six Stirling engine model component palettes - "Basic", "Canisters", "Heat Exchanger", "Phasr Moving Parts", "Gt Moving Parts" and "Composite". A Sage model is a collection of component parts assembled in a graphical edit window by clicking and dragging the components into the window and connected in a particular way to form a complete system. Model components are organized in a hierarchical structure. The root model component contains a number of subcomponents which may themselves contain sub-sub-components. Child (sub) models are accessed by doubleclicking on parent models. The labeled arrows sticking out of the sides of components are boundary connectors. They are joined together as matched pairs with numbers $(2,3$ and 4$)$ identifying the match. The labels are meant to suggest what information is transferred across the connection between components. Sage is also able to perform such functions as open and save files, increase/decrease connector level, copy, cut and paste components.

The gas spring is modeled using Sage's Stirling machine model component palettes. The variable volume gas space in Fig. 1(a) and the charge pressure inside it are modeled in the Sage code using a generic cylinder (renamed "gas spring cylinder" in Fig. 1(b)) and a pressure source both obtained from the "Basic" component palette in the Stirling machine level. The pressure source comes with a built in steady state density connection $\left(\rho_{\text {stdy }}\right)$ and acts as an isobaric gas reservoir in that the density in the gas domain adapts itself so that the time average pressure is continuous across the connection. The cylinder-space gas and isothermal surface, child models of the gas spring cylinder, are obtained from the "Gas Domain" and "Cylinder Walls" component palettes in the gas spring cylinder level. The arrows labeled 2 in the gas spring edit window indicate a space-time varying heat flow connection $\mathrm{Q}_{\mathrm{Gxt}}$ between the z-face of the cylinder-space gas and the isothermal surface. The positive-facing volume displacement phasor and gas charge line, both child models of the cylinder-space gas, are moved up to the Stirling machine level for pressure connections $\left(\mathrm{P}_{\mathrm{phs}}\right)$ to the constrained piston (label 3 ) and density connections $\left(\rho_{\text {stdy }}\right)$ to the pressure source (label 4) respectively. The positive-facing volume displacement phasor represents the volume change of the gas space due to the motion of the piston. The piston in Fig. 1(a) is modeled using the constrained piston obtained from the "Phsr Moving Parts" component palette in the Stirling machine level. Its child model, the negative facingarea phasor, is obtained from the "Mechanical Attachment" component palette in the constrained piston level. Its pressure connection arrow is moved up to the Stirling machine level for connection there to the gas spring cylinder. Figure 1(b) shows the gas spring model components communicate with each other using density ( $\left.\rho_{\text {stdy }}\right)$, heat flow $\left(\mathrm{Q}_{\mathrm{Gxt}}\right)$ and pressure $\left(\mathrm{P}_{\mathrm{phss}}\right)$ boundary connections.

Once a model structure is created in Sage, numerical inputs for the model component are either specified or modified. Sometimes user-defined variables (special output variables) can be added to model components. Sage numerical simulation is initiated after initializing component and overall model parameters. Sage calculations are performed via its solver and optimizer routines.

\section{CFD-ACE+ Gas Spring Model (2-D).}

Figure 1(c) is a 2-D representation of the gas spring model using the CFD-ACE+ code. The CFD-ACE+ code exploits the symmetry of the problem domain to model only one-half of the domain as shown, thereby saving on computer memory space and computational time. CFD-GEOM, CFD-GUI, CFD-ACE and CFD-VIEW are the primary CFD-ACE+ modules used in this study.

The CFD-GEOM module is a general purpose model builder which provides comprehensive interactive geometry construction and grid generation capabilities. The geometry of the gas space, the problem domain of interest, is represented within CFD-GEOM using fundamental geometric entities (points, lines, curves, and surfaces) which can be manipulated (translated, rotated, projected, split, joined, etc.) as desired. Grid generation, the process of discretizing the problem domain with individual cells over which the flow equations are integrated follows the geometric representation of the gas space. The locations of the corner points of these cells constitute the "grid" or 
"mesh" which is stored in a data base. Three grid distribution types are available: Power Law, Hyperbolic Tangent and Geometric. Structured and unstructured grids and different grid sizes can be generated. A baseline structured grid size 19x13 is presented in Figure 1(c) for illustration. The power law grid distribution type is used to obtain a finer grid at the boundaries for more accurate resolution of the flow features.

After modeling is completed, the problem is formulated using CFD-GUI, an advanced graphical user interface that allows complete formulation of the problem. Problem formulation involves specifying the problem type, model options, volume conditions, boundary conditions, initial conditions and the numerical technique needed to solve the flow equations.

After problem formulation, simulation is performed using the CFD-ACE flow solver module. The DTF files created by the CFD-ACE flow solver are loaded directly into CFD-VIEW, an interactive graphics program with many tools to visualize the flow physics, animate transient data sets, as well as to extract data for post processing the numerical results. Tools such as point probe, line probe and strip charts are used to obtain the data of required parameters.

\section{B. MIT “Two-Space” (Gas Spring+Heat Exchanger) Test Rig}

Figure 2(a) below shows a schematic representation of Kornhauser's piston-cylinder-heat exchanger test rig. The test section in this rig is essentially a modified gas spring. It consisted of a fixed cylinder head with an annular opening leading into an annular dead-ended heat exchanger space such that flow can continuously pass between the heat exchanger and cylinder as the cylinder piston expands and compresses the gas more like in a Stirling machine cylinder. Because of the extended heat transfer surface in the annular heat exchanger, the energy flows are more complicated than in a simple gas spring.

The construction of the apparatus from the compressor base to the cylinder space just below the fixed cylinder head including the cylinder bore and piston stroke are consistent with those of the gas spring. The heat exchanger annulus is $44.5 \mathrm{~mm}$ (1.75 in) outside diameter and $39.4 \mathrm{~mm}$ (1.55 in) inside diameter, for a wall-to-wall distance of $2.5 \mathrm{~mm}(0.10 \mathrm{in})$. The annulus is $445 \mathrm{~mm}$ (17.5 in) long, so that a volume ratio of 2.0 for the combined cylinder and heat exchanger resulted in a very small cylinder clearance volume; the cylinder-head distance is nominally $2.9 \mathrm{~mm}$ (0.11 in) at top center position. The heat exchanger entrance has the same cross-sectional dimensions as the heat exchanger itself, the entrance corners being as sharp as could easily be machined. The inner wall of the heat exchanger space is made of steel. The outer wall of the heat exchanger space is steel lined with a $1.98 \mathrm{~mm}(0.078 \mathrm{in})$ layer of bronze-filled TFE (Teflon). This lining was chosen for thermal properties matching those of the Pyrex glass substrate of the surface temperature transducers. The gas spring + heat exchanger dimensions are tabulated in Table 2 below. Model representations of Kornhauser's "two-space" test rig using Sage and CFD-ACE+ are illustrated in Figs. 2(b) and 2(c) respectively and discussed below.

\section{Sage "Two-Space" Model (1-D)}

The Sage model of the "two-space" domain is obtained by modifying the Sage gas spring model via the addition of the annular canister representing the heat exchanger. The generic matrix in Fig. 2(b) represents the internal structure of the heat exchanger and is the child model of the annular canister. It is obtained from the "Matrices" component palette in the annular canister level. The matrix gas and isothermal surface, child models of the generic matrix, are obtained from the "Gas Domain" and "Matrix Solids" component palettes in the generic matrix level. The porosity of the generic matrix is assumed to be 1.0, implying no porous material inside the annular canister. The arrows labeled 2 in the generic matrix edit form indicate a heat flow connection between the matrix gas and the isothermal surface. The positive gas inlet, the child model of the matrix gas, models the gas flowing from the annular canister into the gas spring cylinder. It is obtained from the "Charge/Inlet" component palette in the matrix gas level. The mass flow connection arrow is moved up to the Stirling machine level for connection there to the gas spring cylinder (label 6). The gas spring cylinder and constrained piston models and their child models are as described above for the gas spring model. The only exception is the inclusion of the negative gas inlet as a child model for the gas spring cylinder. It is obtained from the "Charge/Inlet" component palette in the cylinder-space gas level and represents the gas flowing from the gas spring cylinder into the annular canister. The mass flow connection arrow is moved up to the Stirling machine level for connection there to the annular canister (label 6).

\section{CFD-ACE+ "Two-Space" Model (2-D)}

As with the gas spring model, the CFD-ACE+ code exploits the symmetry of the problem domain to model only one-half of the domain. A model of the gas spring + heat exchanger using the CFD-ACE+ code is illustrated in Fig. 2(c) below using a course grid (100x20). 


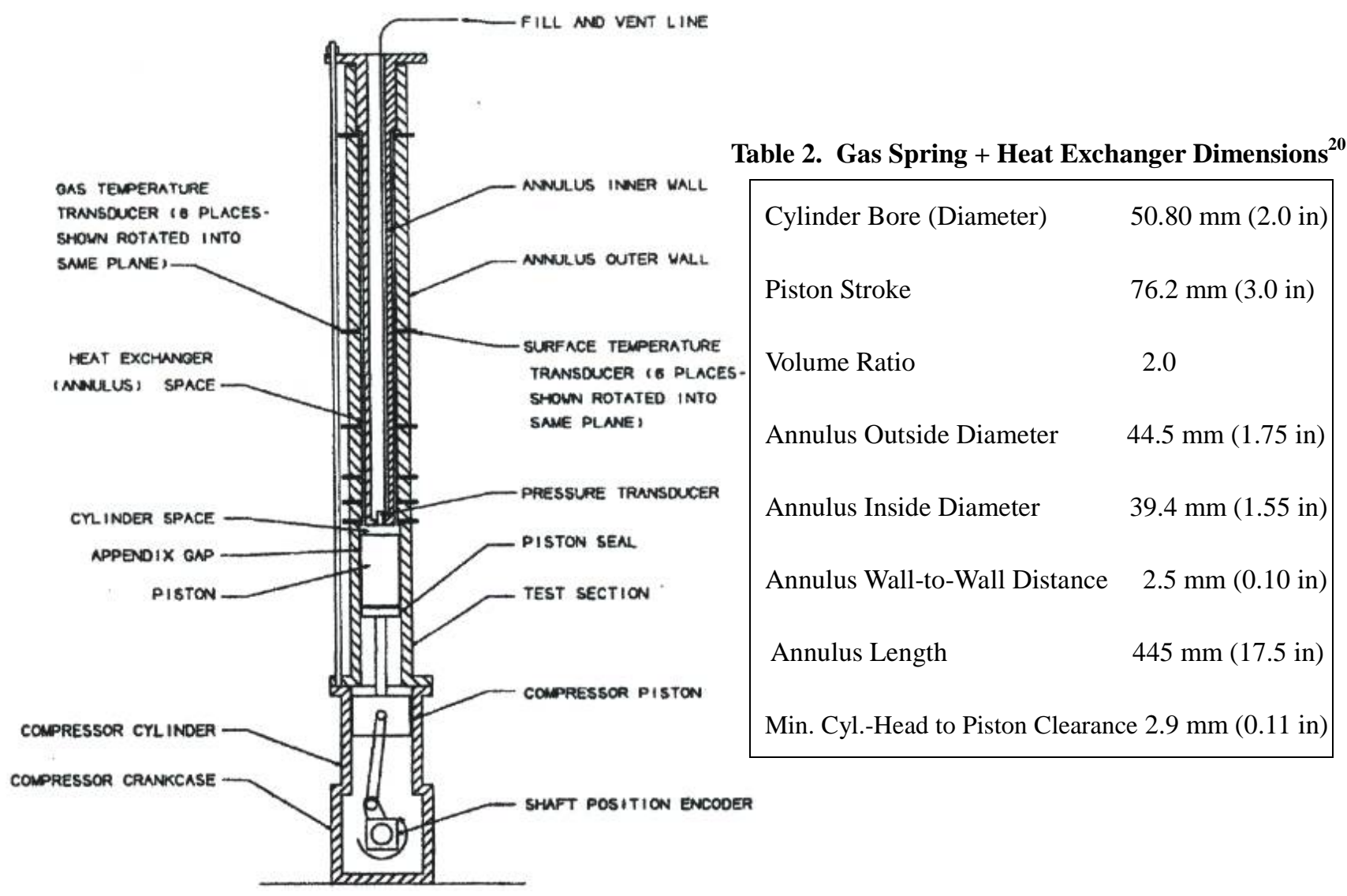

Figure 2(a). Kornhauser's MIT Cylinder + HXer Test Rig.

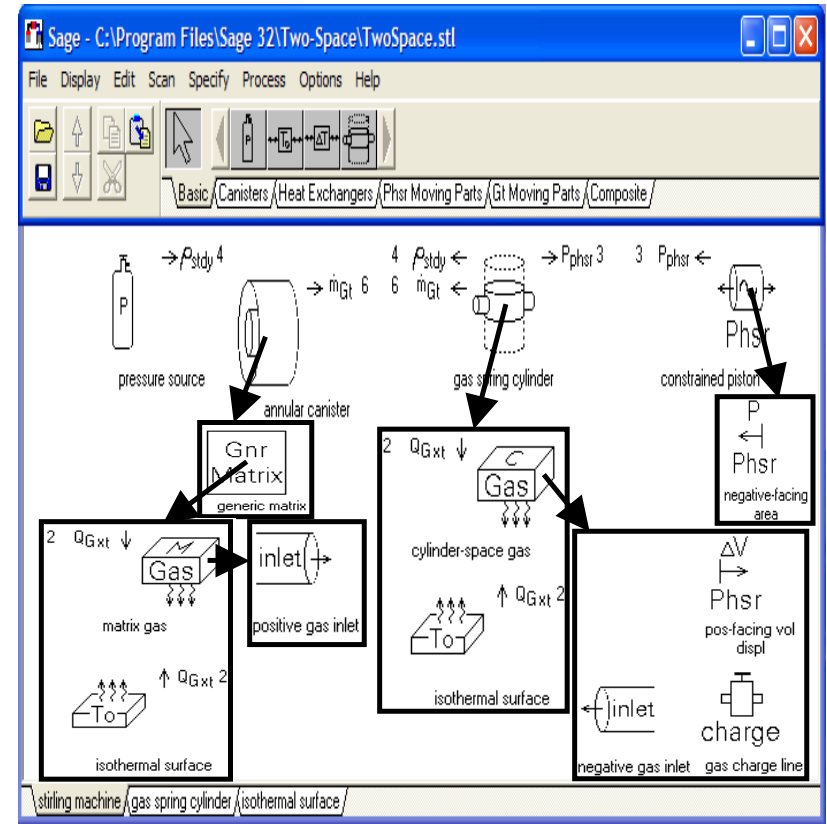

Figure 2(b). Sage Model of Kornhauser's "Two-Space" Domain.

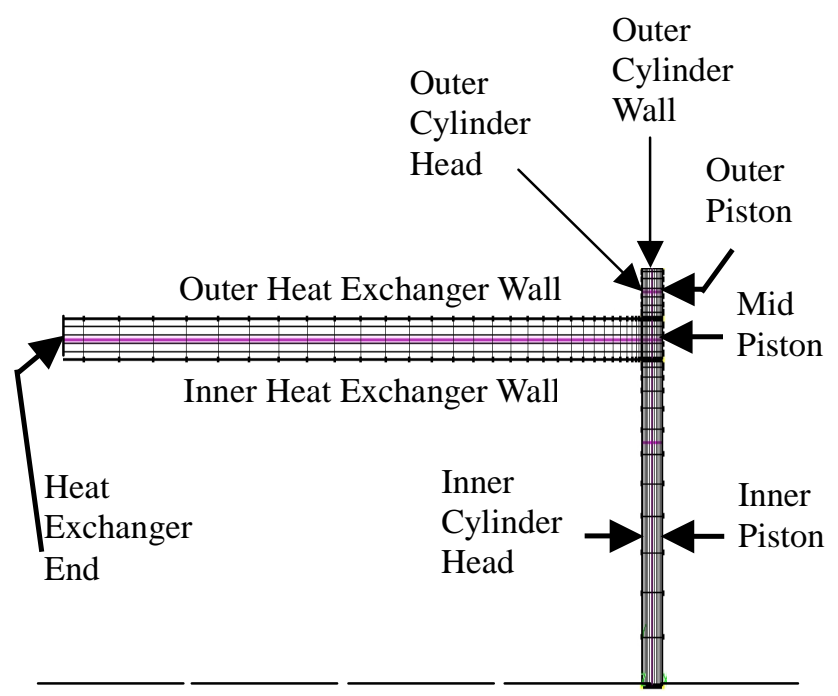

Figure 2(c). CFD-ACE+ Model of Kornhauser's MIT Two Space Domain (Grid Size: $100 \times 20$ ). 


\section{Numerical Simulation Results}

Extensive numerical simulations of the flow and heat transfer phenomena under conditions of oscillating pressure and oscillating fluid flow inside the "single-space" and "two-space" domains were performed using Sage and CFD-ACE+ codes in an earlier study ${ }^{13}$. Simulations using the CFD-ACE+ code were performed following careful optimization studies of the grid size and number of cycles of piston motion using line probe, root mean square (RMS) and energy conservation techniques. The Courant condition ${ }^{19,34}$ was imposed on the choice of the optimum time step. The study cited above compared 1-D Sage vs. 2-D CFD-ACE+ results of energy conservation analyses, temperature, pressure and surface heat transfer variations, and pressure-volume diagrams. Also 2-D CFDACE+ results of surface heat flux, temperature difference between the gas temperature at the radial center of the heat exchanger and the heat exchanger wall, pressure-volume diagrams, velocity vectors, temperature contours and hysteresis loss were compared with experimental and numerical results obtained from the literature ${ }^{20,25,31}$. Important differences and similarities were highlighted between results obtained by the 1-D Sage and the 2-D CFD-ACE+ codes. The 2-D CFD-ACE+ results showed good qualitative agreement with results reported in the literature for both the "single-space" and "two-space" test rigs. For the "two-space" test rig, there were some apparent disagreements in the magnitudes of the heat exchanger heat fluxes and temperature differences. For a more comprehensive evaluation of our numerical simulation results, the reader should consult reference [13]. Overall, the achievement of good energy conservation results and the close agreement with relevant experimental data and numerical results from the literature have enabled us to proceed to focus our current effort on second law analysis post-processing of our numerical results for thermodynamic losses in the MIT test rigs.

\section{Second Law Analysis via Entropy Generation}

The computational analysis of thermo-fluid systems often makes use of the mass, momentum and energy transport equations. For an infinitesimal control volume these equations can be written, respectively, as ${ }^{4,37}$

$$
\begin{gathered}
\frac{D \rho}{D t}=-\rho \nabla \cdot \mathbf{v} \\
\rho \frac{D \mathbf{v}}{d t}=\rho \mathbf{g}-\nabla p+\nabla \cdot \boldsymbol{\tau}_{i j} \\
\rho \frac{D e}{D t}=-\nabla \cdot \mathbf{q}-\nabla \cdot(p \mathbf{v})-w^{\prime \prime \prime}
\end{gathered}
$$

where $\rho$ is density, $\mathrm{t}$ is time, $\mathrm{p}$ is pressure and $\mathrm{T}$ is temperature. The mass specific energy e can be decomposed into mass specific internal, kinetic and potential energies $\left(e=u+1 / 2 V^{2}+g z\right)$. The parameters $\mathbf{q}$ and $\mathbf{v}$ represent, respectively, the heat-flux vector and the velocity vector at points that make up the control surface. The volumetric work transfer rate $\mathrm{w}^{\prime \prime \prime}$ represents the contribution made by the infinitesimal control volume to the overall work transfer rate $\dot{\mathrm{W}}$ delivered by the finite-size control volume. The work term accounts for the flow work, pv ( $\mathrm{v}$ is specific volume), required to push the mass into or out of the control volume and the work done by viscous stresses

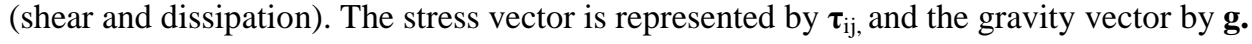

Optimization of thermo-fluid systems requires in addition to the above conservation laws, the application of the second law of thermodynamics.

For a multiport flow system's control volume the general entropy balance which is a statement of the second law can be written as ${ }^{4}$

$$
\dot{\mathrm{S}}_{\mathrm{gen}}=\frac{\mathrm{dS}}{\mathrm{dt}}-\sum_{\mathrm{r}} \dot{\mathrm{Q}}_{\mathrm{r}} / \mathrm{T}_{\mathrm{r}}+\sum_{\mathrm{e}} \dot{\mathrm{m}}_{\mathrm{e}} \mathrm{s}_{\mathrm{e}}-\sum_{\mathrm{i}} \dot{\mathrm{m}}_{\mathrm{i}} \mathrm{s}_{\mathrm{i}} \geq 0
$$

The left-hand side of Eq. (4) represents the rate entropy is generated within the control volume while the right-hand side represents the rate of entropy accumulation inside the control volume minus entropy transfer rate into the control volume via heat transfer plus net entropy flow rate out of the control volume via mass flow. The second law stipulates that entropy generation must be non-negative in all thermo-physical processes. The parameters $S, \dot{Q}_{r}, T_{r}$, $\dot{\mathrm{m}}$ and s denote, respectively, the total entropy, the rate at which heat is transferred into the system, the absolute temperature, the mass flow rate and the mass specific entropy. The subscripts $i$, e and $r$ denote, respectively, inlet 
port, exit port and region on the system boundary across which heat is transferred. An alternate statement of Eq. (4) in integral form can be expressed as ${ }^{4}$

$$
\dot{\mathrm{S}}_{\text {gen }}=\int_{\mathbf{V}} \mathrm{s}_{\text {gen }}^{\prime \prime \prime} \mathrm{d} \mathbf{V}=\int_{\mathbf{V}} \frac{\partial(\rho \mathrm{s})}{\partial \mathrm{t}} \mathrm{d} \mathbf{V}+\int_{\mathbf{A}} \frac{1}{\mathrm{~T}} \mathbf{q} \cdot \mathbf{n} \mathrm{dA}+\int_{\mathbf{A}} \rho \mathrm{s} \mathbf{v} \cdot \mathbf{n} \mathrm{dA}
$$

In this expression, $\mathrm{s}_{\text {gen }}^{\prime \prime \prime}$ is the volume rate of entropy generation, $V$ the volume occupied by the open system, $A$ is the control surface and $\mathbf{n}$, the unit vector that is locally normal to $A$ and points away from the system.

The second-law statement (Eq.5) for an infinitesimal control volume is obtained by transforming the surface integrals in accordance with the divergence theorem and by invoking the mass-continuity equation. The resulting statement for the volumetric entropy generation is

Or,

$$
\mathrm{s}_{\mathrm{gen}}^{\prime \prime \prime}=\rho \frac{\mathrm{Ds}}{\mathrm{Dt}}+\nabla \cdot\left(\frac{\mathbf{q}}{\mathrm{T}}\right)
$$

$$
\mathrm{s}_{\text {gen }}^{\prime \prime \prime}=\rho \frac{\mathrm{Ds}}{\mathrm{Dt}}-\frac{\mathbf{q} \cdot \nabla \mathrm{T}}{\mathrm{T}^{2}}+\frac{\nabla \cdot \mathbf{q}}{\mathrm{T}}
$$

Unlike Eqs. (1-3) which require that mass, momentum and energy be conserved during a process, the second law (Eq.4) postulates the existence of total entropy, S, a non-conserved property of state that can be created via a generation or production term, $\dot{S}_{\text {gen. }}$. Whereas the energy equation (Eq.3) representing the first law of thermodynamics deals with the quantity of energy and transformation of energy from one form to another, the second law asserts that energy varies in its quality or capacity to do useful work. Water at the top of a high cliff is a high quality energy source because it can be used to perform work. We can use the falling water to turn a turbine and produce electricity. But the high quality concentrated energy in the falling water is turned into low quality dispersed heat energy as it reaches the bottom of the cliff. This process of energy degradation is one way of stating the second law of thermodynamics. The second law is the law of energy degradation. During any chemical or physical process the quality or capacity of the energy to perform work is irretrievably lost. The irreversible reduction in energy quality described by the second law of thermodynamics fits with our common-sense notion that something is lost when we burn fuel. We don't lose quantity - it is conserved as the first law tells us - but the second law tells us that what we lose is energy quality, or the capacity to perform useful work.

The second law analysis via entropy generation is concerned mainly with losses due to internal irreversibilities. As noted earlier, viscous friction, heat transfer and non-equilibrium processes are the three fundamental mechanisms that generate entropy within thermo-fluid systems. Increase in entropy gives a measure of the extent to which the energy of a system is lost or unavailable for work during a certain process. It is therefore desirable to study the various mechanisms responsible for entropy generation in order to minimize it in engineering equipment. Entropy generation may be calculated in one of two ways: by entropy flow across the external boundaries of a system (external entropy generation) or by entropy generated by internal processes (internal entropy generation). In principle, the two methods of accounting should give the same answer. Discrepancies which usually arise are often attributable to numerical errors (finite-difference truncation errors, round-off errors, interpolation errors, etc.).

\section{A. External Entropy Generation}

The cyclic integral of Eq. (5) accounts for the external entropy generation from the MIT test rig:

$$
\dot{\mathrm{S}}_{\text {gen, cyl (ext) }}=\oint_{\text {Period }} \int_{\mathrm{A}} \frac{\mathbf{q} \cdot \mathbf{n}}{\mathrm{T}} \mathrm{dAdt}+\oint_{\text {Period }} \int_{\mathrm{A}} \rho \mathrm{s} \mathbf{v} \cdot \mathbf{n} \mathrm{dA} \mathrm{dt}
$$

The integral terms are the net entropy transfer with heat and mass out of the system into the surrounding environment. The external entropy calculation is made just over the surface between the internal calculation domain and the environment. 


\section{B. Internal Entropy Generation}

Internal entropy generation can be accounted for by tallying up the individual entropy generations in all internal processes. For the MIT test rigs considered in this study, possible internal entropy generation mechanisms include conductive heat flow in a temperature gradient and viscous dissipation resulting in mixing loss. That is:

$$
\dot{\mathrm{S}}_{\text {gen (int) }}=\dot{\mathrm{S}}_{\text {gen, cond }}+\dot{\mathrm{S}}_{\text {gen, visc diss }}
$$

Consider the differential energy equation that is valid for a Newtonian fluid under very general conditions of unsteady, compressible, viscous, heat-conducting flow ${ }^{24}$

$$
\rho \frac{\mathrm{Dh}}{\mathrm{Dt}}=\mathrm{k} \nabla^{2} \mathrm{~T}+\frac{\mathrm{Dp}}{\mathrm{Dt}}+\Phi
$$

Note that this equation is essentially derived from Eq. (3) by incorporating the flow work in the specific enthalpy term $(h=u+p v)$ thus accounting for thermal energy being convected in and out of the control volume. The shear stress is eliminated in the work term (along with the kinetic and potential energies) by the introduction of the linear momentum equation (Eq.2) leaving only the viscous dissipation term $\Phi$. Radiation heat transfer and internal sources of heat that might occur during a chemical or nuclear reaction are neglected leaving only conduction heat transfer. The parameters $\mathrm{k}$ and $\mathrm{p}$ denote the thermal conductivity, and pressure respectively. The viscous dissipation function $\Phi$ has the form

$$
\begin{aligned}
\Phi & =2 \mu\left[\left(\frac{\partial \mathrm{u}}{\partial \mathrm{x}}\right)^{2}+\left(\frac{\partial \mathrm{v}}{\partial \mathrm{y}}\right)^{2}+\left(\frac{\partial \mathrm{w}}{\partial \mathrm{z}}\right)^{2}+\frac{1}{2}\left(\frac{\partial \mathrm{u}}{\partial \mathrm{y}}+\frac{\partial \mathrm{v}}{\partial \mathrm{x}}\right)^{2}+\frac{1}{2}\left(\frac{\partial \mathrm{v}}{\partial \mathrm{z}}+\frac{\partial \mathrm{w}}{\partial \mathrm{y}}\right)^{2}+\frac{1}{2}\left(\frac{\partial \mathrm{u}}{\partial \mathrm{z}}+\frac{\partial \mathrm{w}}{\partial \mathrm{x}}\right)^{2}\right] \\
& =2 \mu\left[\left(\frac{\partial \mathrm{u}}{\partial \mathrm{x}}\right)^{2}+\left(\frac{\partial \mathrm{v}}{\partial \mathrm{y}}\right)^{2}+\frac{1}{2}\left(\frac{\partial \mathrm{u}}{\partial \mathrm{y}}+\frac{\partial \mathrm{v}}{\partial \mathrm{x}}\right)^{2}\right]
\end{aligned}
$$

where $\mu$ is the dynamic viscosity and $\mathrm{u}, \mathrm{v}$, and $\mathrm{w}$ denote Cartesian velocity components. The density $\rho$ and enthalpy $\mathrm{h}$ are provided by data or algebraic expressions for state relations of thermodynamic properties e.g., $\rho=\rho(\mathrm{p}, \mathrm{T})$ and $\mathrm{h}=\mathrm{h}(\mathrm{p}, \mathrm{T})$. In principle, compressible flow calculations can be made for any fluid equation of state. But in fact most elementary treatments are confined to monatomic ideal gases with constant specific heats such as helium, the working gas in the MIT test rigs. For these gases

$$
\rho=\frac{\mathrm{p}}{\mathrm{RT}}, \quad \mathrm{R}=\mathrm{c}_{\mathrm{p}}-\mathrm{c}_{\mathrm{v}}=\text { const }
$$

The parameter $\mathrm{R}$ is the gas constant and $\mathrm{c}_{\mathrm{p}}$ and $\mathrm{c}_{\mathrm{v}}$ are the specific heats at constant pressure and volume respectively.

Explicit relations for differential changes in entropy can be obtained by solving for ds in the second Tds equation $^{5}$

$$
\mathrm{Tds}=\mathrm{dh}-\mathrm{vdp}
$$

By substituting $v=1 / \rho$ into Eq. (13) the differential entropy change becomes

$$
\mathrm{ds}=\frac{\mathrm{dh}}{\mathrm{T}}-\frac{1}{\rho} \frac{\mathrm{dp}}{\mathrm{T}}
$$

Eq. (14) can be expressed in terms of the material derivative of the entropy as

$$
\rho \frac{\mathrm{Ds}}{\mathrm{Dt}}=\frac{\rho}{\mathrm{T}} \frac{\mathrm{Dh}}{\mathrm{Dt}}-\frac{1}{\mathrm{~T}} \frac{\mathrm{Dp}}{\mathrm{Dt}}
$$

If we now substitute Eq. (10) in Eq. (15) we get after simplification

$$
\rho \frac{\mathrm{Ds}}{\mathrm{Dt}}=\frac{\mathrm{k} \nabla^{2} \mathrm{~T}}{\mathrm{~T}}+\frac{\Phi}{\mathrm{T}}
$$


Subst. Eq. (16) in Eq. (7) gives after simplification:

$$
\begin{gathered}
\mathrm{s}_{\text {gen }}^{\prime \prime \prime}=-\frac{\mathbf{q} \cdot \nabla \mathrm{T}}{\mathrm{T}^{2}}+\frac{\Phi}{\mathrm{T}} \\
\text { or, } \quad \mathrm{s}_{\text {gen }}^{\prime \prime \prime}=\frac{\mathrm{k}}{\mathrm{T}^{2}}\left[\left(\frac{\partial \mathrm{T}}{\partial \mathrm{x}}\right)^{2}+\left(\frac{\partial \mathrm{T}}{\partial \mathrm{y}}\right)^{2}\right]+\frac{2 \mu}{\mathrm{T}}\left[\left(\frac{\partial \mathrm{u}}{\partial \mathrm{x}}\right)^{2}+\left(\frac{\partial \mathrm{v}}{\partial \mathrm{y}}\right)^{2}+\frac{1}{2}\left(\frac{\partial \mathrm{u}}{\partial \mathrm{y}}+\frac{\partial \mathrm{v}}{\partial \mathrm{x}}\right)^{2}\right]
\end{gathered}
$$

The internal entropy generation due to conductive heat flow and viscous dissipation in the MIT test rig can thus be expressed in integral form as:

$$
\dot{\mathrm{S}}_{\text {gen, cyl (int) }}=-\oint_{\text {Period }} \int_{\mathrm{V}} \frac{\mathbf{q} \cdot \nabla \mathrm{T}}{\mathrm{T}^{2}} \mathrm{dV} \mathrm{dt}+\oint_{\text {Period }} \int_{\mathrm{V}} \frac{\Phi}{\mathrm{T}} \mathrm{dV} \mathrm{dt}
$$

The first term on the right-hand side of Eq. (18) which involves the squares of the temperature gradients is the entropy generation due to conductive heat flow while the second term which involves the squares of the velocity gradients is the contribution due to viscous dissipation. The sum of these two terms seems to account for all of the internal thermodynamic losses. The viscous dissipation term accounts for mixing loss in the flow field. Mixing loss is generated by mixing of the flow field due to the shear stress between fluid layers, vortices resulting from wall flow separation or shed vortices in the core of the fluid. A control volume approach can be used quite successfully to calculate the viscous dissipation term and hence the total mixing loss. Errors in the mixing loss are likely to be small, since all mixing processes obey the fundamental conservation equations that also govern the behavior of the numerical predictions. The difficulties found in using numerical predictions to estimate the mixing losses are thought to be due to false entropy due to numerical dissipation ${ }^{10}$. Although mixing is only a relatively short-lived phenomenon as the flow eventually mixes out completely, it is a major contributor to the total loss. This is especially true for turbulent flows where the effective viscosity is very large.

Equation (18) seems to imply that the internal thermodynamic losses can be minimized by minimizing the magnitude of these local temperature and velocity gradients and the sum of their squares, throughout the domain of interest. These measures are however difficult or impractical to implement. For example, it is not practical to reduce the fluid viscosity which would lead to a reduction of the velocity gradients at the wall and the boundary layer viscous losses. Also, it is not practical to increase the fluid thermal conductivity which would reduce the temperature gradients at the wall, and the conductive heat transfer loss.

\section{Availability Energy Loss}

All internal entropy generations can also be characterized in terms of availability energy loss defined as ${ }^{5}$ :

$$
\text { Availability Loss }=\mathrm{W}_{\mathrm{r}}-\mathrm{W}_{\mathrm{i}}
$$

where $\mathrm{W}_{\mathrm{r}}$ and $\mathrm{W}_{\mathrm{i}}\left(<\mathrm{W}_{\mathrm{r}}\right)$ are the net mechanical work available from reversible and irreversible heat engines respectively; both obtained from the same heat input $\dot{\mathrm{Q}}_{\text {in }}$ and operating between a high temperature reservoir at temperature $\mathrm{T}_{\mathrm{H}}$ and a low temperature reservoir at temperature $\mathrm{T}_{\mathrm{L}}$.

The efficiency of a heat engine is defined as

$$
\eta_{\text {th }}=\frac{\dot{\mathrm{W}}_{\text {net, out }}}{\dot{\mathrm{Q}}_{\text {in }}}=1-\frac{\dot{\mathrm{Q}}_{\text {out }}}{\dot{\mathrm{Q}}_{\text {in }}}
$$

From this definition, the net heat outflow for the irreversible heat engine $\dot{Q}_{0, i}$ should be greater than the net heat outflow for the reversible heat engine, $\dot{Q}_{o, r}$.

For the reversible heat engine ${ }^{5}$

$$
\eta_{\mathrm{th}, \mathrm{rev}}=\frac{\dot{\mathrm{W}}_{\mathrm{r}}}{\dot{\mathrm{Q}}_{\mathrm{in}}}=1-\frac{\mathrm{T}_{\mathrm{L}}}{\mathrm{T}_{\mathrm{H}}}
$$


where the Kelvin thermodynamic temperature scale $\left(\dot{\mathrm{Q}}_{\mathrm{in}} / \dot{\mathrm{Q}}_{\text {out }}\right)_{\text {rev }}=\mathrm{T}_{\mathrm{H}} / \mathrm{T}_{\mathrm{L}}$ has been used ${ }^{5}$.

Thus:

$$
\dot{\mathrm{W}}_{\mathrm{r}}=\dot{\mathrm{Q}}_{\text {in }}\left(1-\frac{\mathrm{T}_{\mathrm{L}}}{\mathrm{T}_{\mathrm{H}}}\right)
$$

and

$$
\dot{\mathrm{W}}_{\mathrm{i}}=\dot{\mathrm{Q}}_{\text {in }}\left(1-\frac{\dot{\mathrm{Q}}_{\mathrm{o}, \mathrm{i}}}{\dot{\mathrm{Q}}_{\text {in }}}\right)
$$

Substituting Eqs. (22 and 23) in Eq. (19) gives, after simplification:

$$
\text { Availability Loss }=-\mathrm{T}_{\mathrm{L}}\left(\frac{\dot{\mathrm{Q}}_{\mathrm{in}}}{\mathrm{T}_{\mathrm{H}}}-\frac{\dot{\mathrm{Q}}_{\mathrm{o}, \mathrm{i}}}{\mathrm{T}_{\mathrm{L}}}\right)
$$

For steady periodic process in a closed system, $\frac{\mathrm{dS}}{\mathrm{dt}}=0$ and $\dot{\mathrm{m}}=0$. Substituting the simplified Eq. (4) in Eq. (24):

$$
\text { Availability Loss }=\mathrm{T}_{\mathrm{L}} \dot{\mathrm{S}}_{\text {gen }}
$$

The availability-loss concept allows us to think about entropy generation in terms of the more concrete notion of lost mechanical work. A loss in availability equates to a decrease of PV power in an engine. For example, in turbo-machines that generate shaft power (turbines) or absorb power (pumps, compressors), the rate of power lost owing to irreversibilities is proportional to a loss in availability and thus to the rate of entropy generation.

The results of the second law analysis via entropy generation can be summarized as follows:

External Entropy Generation:

$$
\dot{\mathrm{S}}_{\text {gen, cyl (ext) }}=\oint_{\text {Period }} \int_{\mathrm{A}} \frac{\mathbf{q} \cdot \mathbf{n}}{\mathrm{T}} \mathrm{dAdt}+\oint_{\text {Period }} \int_{\mathrm{A}} \rho \mathrm{s} \mathbf{v} \cdot \mathbf{n} \mathrm{dA} \mathrm{dt}
$$

Internal Entropy generation:

Conductive heat flow:

$$
\dot{\mathrm{S}}_{\text {gen, cyl(int) (cond) }}=-\oint_{\text {Period }} \int_{\mathrm{V}} \frac{\mathbf{q} \cdot \nabla \mathrm{T}}{\mathrm{T}^{2}} \mathrm{dV} \mathrm{dt}
$$

Viscous Dissipation:

$$
\dot{\mathrm{S}}_{\text {gen, cyl(int) (visc) }}=\oint_{\text {Period }} \int_{\mathrm{V}} \frac{\Phi}{\mathrm{T}} \mathrm{dV} \mathrm{dt}
$$

Availability Loss:

$$
\text { Availability Loss }=\mathrm{T}_{\mathrm{L}} \dot{\mathrm{S}}_{\text {gen }}
$$




\section{Second Law Analysis Post Processing of Numerical Simulation Results}

Equations (26-28) clearly show that local entropy production depends functionally on the local values of heat transfer rate, temperature, density, mass-specific entropy, velocity and viscous dissipation. Thus entropy generation can be considered a derived quantity that can be computed by post-processing experimental or numerical flow fields. Equation (29) shows that local entropy production is a function of availability loss and temperature.

\section{A. Using Sage}

Sage entropy generation results for both test rigs are calculated from Eq. (29) using availability loss results obtained from Sage output file viz.:

$$
\dot{\mathrm{S}}_{\text {gen }}=\frac{\text { Availability Loss }}{\mathrm{T}_{\mathrm{L}}}=\frac{\text { AEfric }+ \text { AEQw }+ \text { AEQx } \pm \mid \text { AEDiscr } \mid}{\mathrm{T}_{0}}
$$

The parameters AEfric, AEQw, and AEQx are available energy losses due to flow friction, surface heat flow and axial heat flow respectively. |AEDiscr| is the absolute value of the discrepancy between the total available energy loss due to internal entropy generation (AEinternal = AEfric + AEQw + AEQx) and that due to external entropy generation, AEexternal. The "+" is used when it is assumed that AEexternal is greater than AEinternal and the ""sign is used when the reverse is the case. These assumptions are arbitrary since the relative magnitudes of AEexternal and AEinternal cannot be determined apriori. A discrepancy of zero implies the total available energy loss due to internal entropy generation is equal to that due to external entropy generation.

\section{B. Using CFD-ACE+}

1. External Entropy Generation, $\dot{\mathrm{S}}_{\mathrm{gen}(\mathrm{ext} .)}$

The "single-space" and "two-space" models each taken as a whole constitutes a closed, isothermal, nonadiabatic, reciprocating system. Eq. (26) is thus reduced to

$$
\dot{\mathrm{S}}_{\text {gen (ext) }}=\oint_{\text {Period }} \int_{\mathrm{A}} \frac{\mathbf{q} \cdot \mathbf{n}}{\mathrm{T}} \mathrm{dAdt}
$$

in which case results of surface heat transfer and temperature only are post-processed. Whereas the "single-space" model is limited to the use of Eq. (31) because of its simple closed system construction, the "two-space" model can also be analyzed, by considering its separate components - the heat exchanger space and the cylinder space - as open systems. For open systems, Eq.(26) is applicable and CFD-ACE+ generated results of surface heat transfer, temperature, mass flow rate and mass specific entropy are post-processed for external entropy generation. Figure 3 shows the "single-space" model (Fig.3(a)) set up as a single cylinder volume condition for analysis. In order to simplify the analysis, the "two-space" model (Fig.3(b)) was partitioned into four volume conditions - outer, mid and inner cylinder volume conditions in the cylinder space plus the heat exchanger constituting a single volume condition. The external entropy generation is calculated for each volume condition with the sum of the results for the separate volume conditions yielding the total external entropy generation for the "two-space" model.

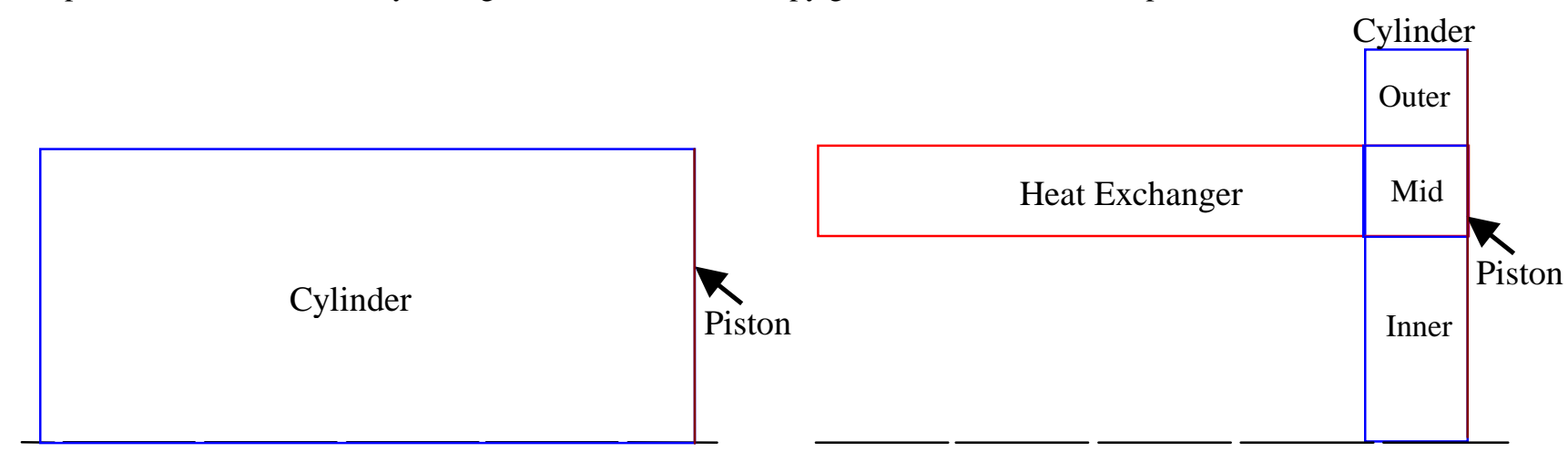

Axis of Symmetry

Axis of Symmetry

(a). "Single-Space" Model

(b). “Two-Space” Model

Figure 3. Model Set-Up for External Entropy Generation Analysis 
Integrated surface heat transfer rates generated each time step can be stored in output data files called assembly files. An assembly file is enabled by first creating an input file ("filename.fmt"), which specifies the relevant system bounding surfaces, in Notepad (facility for creating and editing text files using basic text formatting) and then choosing the "BC Integral Output" option in CFD-ACE-GUI. To calculate the external entropy generation for the "single-space" model using assembly file data, the integrated heat transfer rate data are exported to an Excel spreadsheet for calculation of the cyclic time integral value (see Eq. 31). Division of the cyclic integral value by the constant surface temperature completes the calculation of the external entropy generation. The same procedure applies for the "two-space" model if it is analyzed as a closed system. If the "two-space" model is analyzed by considering its separate components as open systems, as done in this study, CFD-ACE+ generated results are postprocessed for the external entropy generation by using a user subroutine interfaced with the CFD-ACE+ solver. Note that post-processing of assembly file data is only possible for closed systems. User subroutines can be used to postprocess any CFD-ACE+ generated closed or open system data. User subroutines, especially necessary for open systems, require an in-depth knowledge of Fortran concepts.

\subsection{User Subroutines}

User subroutines are written in FORTRAN 90 to post-process CFD-ACE+ generated surface heat transfer, temperature, velocity gradients, mass flow and mass specific entropy data. The discretized domain of interest (interior and bounding surfaces) consists of cells (interior) and short line segments called "faces" (boundary) as shown in Figure 4 below.

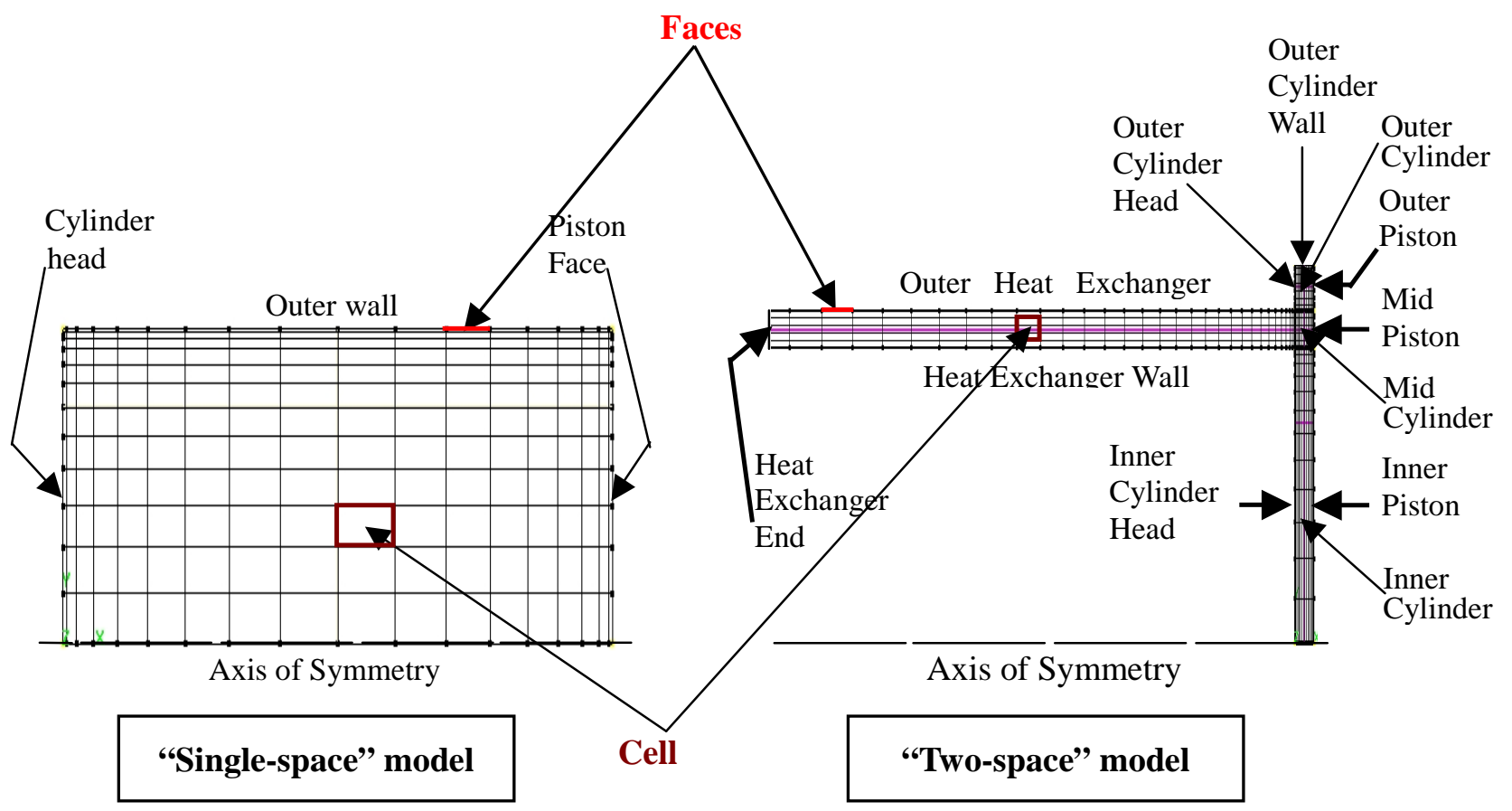

Figure 4. Discretized computational domain showing "faces" and "cells"

Surface heat transfer, temperature, velocity and temperature gradients, mass flow and mass specific entropy values can be obtained at cell or "face" centers except at the interface between volume conditions where data values can only be obtained at cell centers near the interface. The velocity and temperature gradient values at cell centers can either be obtained directly from "get gradient function" module in CFD-ACE+ or calculated using finite difference approximations for the non uniform grid spacing in the computational domain ${ }^{29}$. The summation of surface, volume and time values, implied by the integrals in Eqs. (26 - 28) is facilitated with the use of do loops in the subroutines. In order to minimize program complexity, the subroutines are written to sum up the surface and volume integral values at each time step only and thereafter data is exported to an Excel spreadsheet for calculation of the cyclic time integrals. A carefully constructed algorithm is needed for implementation of Eqs. (26-28). 


\section{Internal Entropy Generation, $\dot{\mathrm{S}}_{\text {gen (int). }}$}

The volume conditions in the model may be further refined for calculation of internal entropy generation as shown in Figure 5 below in order to obtain a better resolution of the losses. Equations (27) and (28) are used to calculate the internal entropy generation due to conductive heat flow and viscous dissipation respectively. Results of heat transfer, temperature and gradients of temperature and velocity are post-processed via user subroutines written for both MIT models. Local and global distribution of entropy generation rates due to conductive heat flow and viscous dissipation can be evaluated via a histogram map.

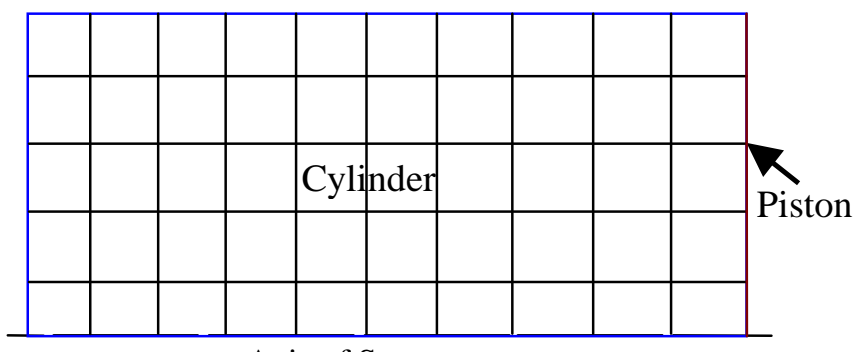

Axis of Symmetry

(a). "Single-Space" Model

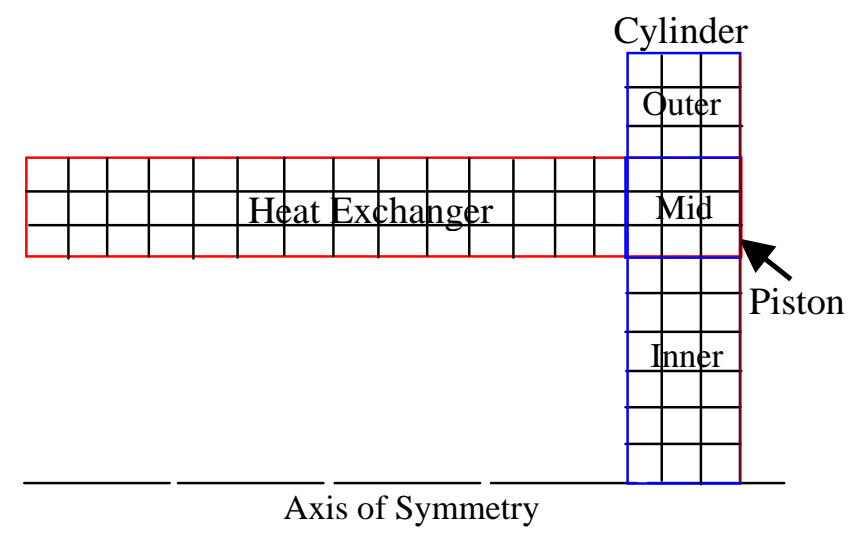

(b). "Two-Space" Model

Figure 5. Model Set-Up for Internal Entropy Generation Analysis 


\section{Results and Discussion}

The results of the post-processing analysis are shown and discussed below for the indicated models and operating conditions.

\section{A. Gas Spring}

Figure 6 illustrates the CFD-ACE+ results of the external and internal entropy generations as functions of the number of cycles of piston motion in the gas spring model. A negative external entropy generation which appears to violate the second law is noted for the first cycle of piston motion. This amounts to an effective source term in the Navier-Stokes equations because of initial transients generated by the moving piston in a flow field that is initially not properly defined.

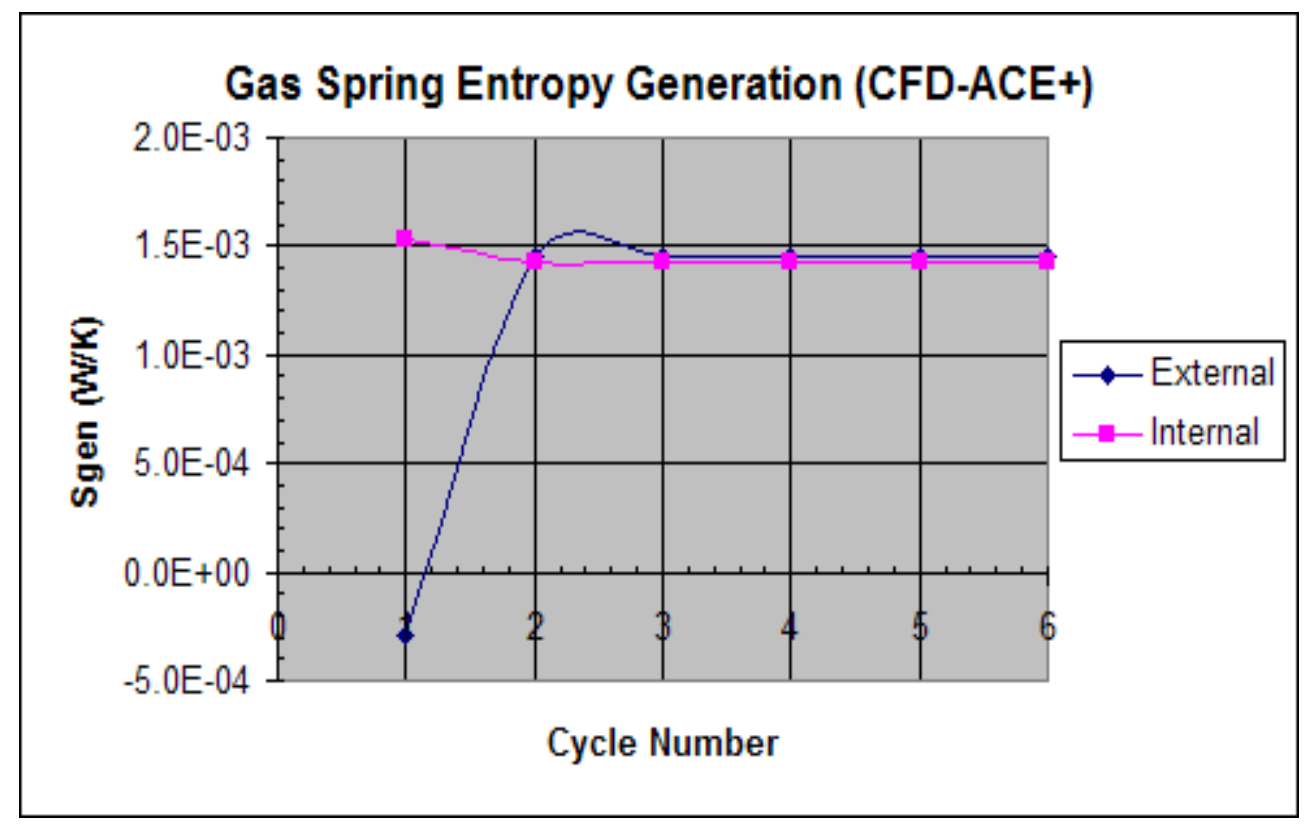

Figure 6. Gas spring entropy generation vs. Cycle number

$\left(10 \mathrm{RPM}, 192.4 \mathrm{kPa}\right.$., $\mathrm{T}_{\text {wall }}=294 \mathrm{~K}$, Grid size $=32 \times 20$, \#tspc $\left.=480\right)$.

The internal entropy generation appears insensitive to the number of cycles of piston motion one cycle earlier than does the external entropy generation and from the third cycle onward the two methods of accounting for the entropy generation appear to yield essentially the same result as they should in principle. The $\sim 1.3 \%$ discrepancy between the external and internal entropy generation results is insignificant and probably due to numerical errors for the internal calculations. As expected, the external entropy generation profile is the mirror image of the graph of $\oint \delta \mathrm{Q} / \mathrm{T}$ in the energy conservation plot (Fig. 6(a), [13]).

Table 3 below shows Sage and CFD-ACE+ entropy and availability energy loss results for the gas spring. All CFD-ACE+ results, with the exception of the external entropy generation, are less than corresponding Sage results. Sage results show that the primary contribution to the total availability energy loss is the energy loss to surface heat flow (AEQw). With no contributions from flow friction (AEfric) and axial heat flow (AEQx) and negligible numerical errors as reflected by a discrepancy value of 1.031E-06 (W), Sage appears to have completely satisfied the principle that the two methods of accounting for the entropy generation should give the same answer. CFDACE+ calculates about $1.3 \%$ difference between internal and external entropy generation values and therefore does not satisfy the accounting principle as well as Sage.

The percentage differences in the internal and external availability energy loss results between Sage and CFDACE+ are on the average about a factor of 3.4 greater than the corresponding entropy generation results. The external results show better agreement between Sage and CFD-ACE+ than corresponding internal results by an average factor of about 1.7. This is not surprising, since internal entropy calculations using 1-D Sage code are expected to incur more errors where the flow features inside the gas spring are more two-dimensional than one- 
Table 3. Gas Spring Entropy Generation and Availability Energy Loss (Sage vs. CFD-ACE+)

\begin{tabular}{|c|c|c|c|c|}
\hline \multicolumn{5}{|c|}{ Gas Spring } \\
\hline \multicolumn{3}{|c|}{$\begin{array}{c}\text { Sage } \\
\left(\mathrm{T}_{\text {wall }}=300 \mathrm{~K}\right)\end{array}$} & \multicolumn{2}{|c|}{$\begin{array}{c}\text { CFD-ACE+: V2004 (Alpha version }) \\
\left(10 \mathrm{RPM}, 192.4 \mathrm{kPa} ., \mathrm{T}_{\text {wall }}=294 \mathrm{~K},\right) \\
(\text { Grid size }=32 \times 20, \# \mathrm{tspc}=480, \text { Opt. Cycle }=4)\end{array}$} \\
\hline \multicolumn{2}{|c|}{ Internal } & External & Internal & External \\
\hline \multicolumn{5}{|c|}{ Entropy Generation (W/K) } \\
\hline \multicolumn{2}{|c|}{$\dot{\mathrm{S}}_{\text {gen, int }}=\frac{\mathrm{AEfric}+\mathrm{AEQw}+\mathrm{AEQx}}{\mathrm{T}_{\text {wall }}}$} & $\dot{\mathrm{S}}_{\text {gen,ext. }}=\frac{\mathrm{AEfric}+\mathrm{AEQw}+\mathrm{AEQx}-|\mathrm{AEDiscr}|}{\mathrm{T}_{\text {wall }}}$ & $\dot{\mathrm{S}}_{\text {gen, int. }}=\dot{\mathrm{S}}_{\mathrm{gen}, \mathrm{cond}}+\dot{\mathrm{S}}_{\mathrm{gen}, \mathrm{visc}}$ & $\dot{\mathrm{S}}_{\mathrm{gen}, \mathrm{ext}}=-\oint_{\mathrm{dtdd}} \int_{\mathrm{T}} \frac{\mathrm{n} \cdot \mathrm{q}}{\mathrm{T}}$ \\
\hline \multicolumn{2}{|c|}{0.001444667} & 0.001444667 & 0.001432516 & 0.001451513 \\
\hline \multicolumn{5}{|c|}{ Availability Energy Loss (W) } \\
\hline \multicolumn{2}{|c|}{$\mathrm{AE}_{\mathrm{int}}=\mathrm{AEfric}+\mathrm{AEQw}+\mathrm{AEQx}$} & $\mathrm{AE}_{\text {ext }}=\mathrm{AEfric}+\mathrm{AEQw}+\mathrm{AEQx}-|\mathrm{AEDiscr}|$ & $\mathrm{AE}_{\text {int }}=\mathrm{T}_{\text {wall }} \dot{\mathrm{S}}_{\mathrm{gen}, \mathrm{int}}$ & $\mathrm{AE}_{\text {ext }}=\mathrm{T}_{\text {wall }} \dot{\mathrm{S}}_{\text {gen, ex }}$ \\
\hline \multicolumn{2}{|c|}{0.433400000} & 0.433400000 & 0.421159704 & 0.426744822 \\
\hline AEfric & $0.000 \mathrm{E}+00$ & --------- & ---------- & ---------- \\
\hline AEQw & $4.334 \mathrm{E}-01$ & --------- & --------- & --------- \\
\hline AEQx & $0.000 \mathrm{E}+00$ & --------- & ---------- & ---------- \\
\hline AEDiscr & & $1.031 \mathrm{E}-06$ & ---------- & ---------- \\
\hline \multicolumn{5}{|c|}{ |\% Difference| between Internal and External Entropy Generation (or Availability Energy Loss) } \\
\hline \multicolumn{3}{|r|}{0.0} & \multicolumn{2}{|l|}{1.3} \\
\hline & & \multicolumn{3}{|c|}{ |\% Difference| between Sage and V2004 (Alpha version) } \\
\hline & & Internal & \multicolumn{2}{|c|}{ External } \\
\hline \multicolumn{2}{|c|}{ Entropy Generation } & 0.8 & \multicolumn{2}{|c|}{0.5} \\
\hline \multicolumn{2}{|c|}{ Availability Energy Loss } & 2.9 & \multicolumn{2}{|l|}{1.6} \\
\hline
\end{tabular}

dimensional such as during the expansion stroke at crank angle $\theta=10^{\circ}$ and $180^{\circ}$ and compression stroke at $\theta$ $=350^{\circ}$ and $360^{\circ}$ when the flow fields show large recirculation zones [13]. CFD-ACE+ is more suited to handle multidimensional flow situations. 


\section{B. Gas Spring + Heat Exchanger}

Figures 7 and 8 below illustrate the CFD-ACE+ results of the external and internal entropy generations respectively for each of the "two-space" sub-domains. Figure 7(a) shows the functional dependence of entropy generation on the number of cycles of piston motion and Figure 7(b) shows a histogram of the entropy generation values characterizing the contributions of each sub-domain to the external entropy generation. Figures 8 (a) and 8 (b) illustrate corresponding CFD-ACE+ results for the internal entropy generation.

- As with the gas spring domain, Fig. 7(a) shows the external entropy generation plots to be independent of the number of cycles of piston motion beyond the third cycle. Also, the total external entropy generation plot is a mirror image of the graph of $\oint \delta \mathrm{Q} / \mathrm{T}$ in the energy conservation plot (Fig. 6(b), [13]). The negative values for the external entropy generation in the cylinder sub-domains should be interpreted as the cylinder acting as "entropy sink". That is, these sub-domains appear to extract entropy from their surroundings (due to heat entering the cylinder in these sub-domains).

\section{External Entropy Generation from “Two-Space” Sub-domains (CFD-ACE+)}
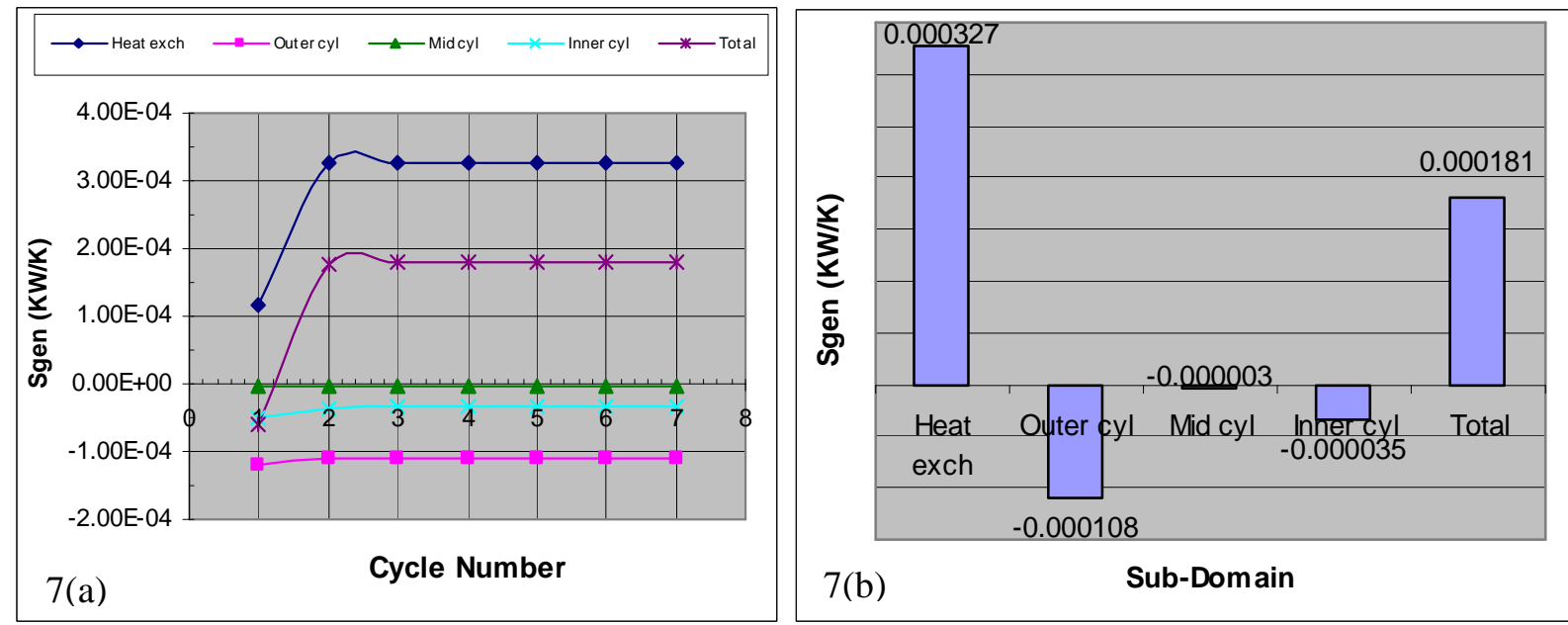

Internal Entropy Generation in "Two-Space” Sub-domains (CFD-ACE+)
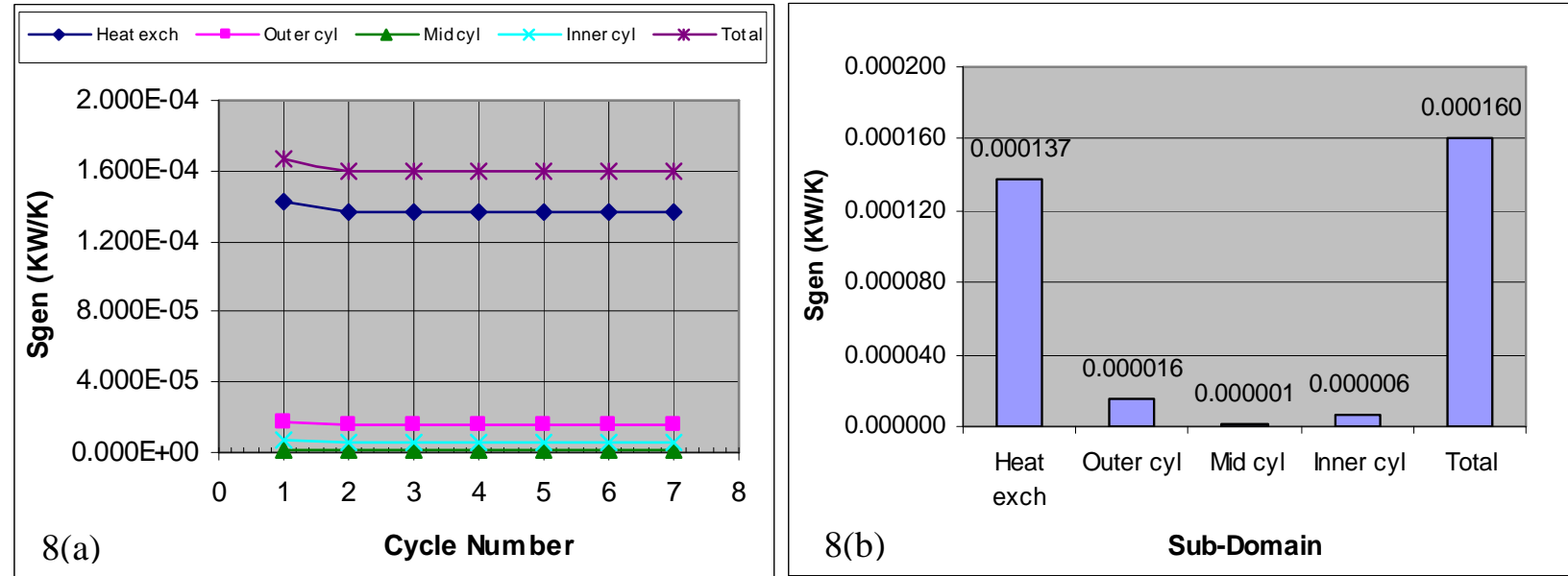

Figures 7\&8. “Two-Space” External (7a,b) and Internal (8a,b) Entropy Generation vs. Cycle Number and Sub-Domain $\left(201.7\right.$ RPM, 1.008 MPa., $T_{\text {wall }}=294 \mathrm{~K} ;$ Grid size $=147$ x 51, \#tspc = 480 $)$.

Fig. 8(a) shows the internal entropy generation plots to be independent of the number of cycles of piston motion one cycle earlier than does the external entropy generation plots, as was the case in the gas spring model. It is noted that the heat exchanger contributes more to the total external entropy generation than it does to the total internal 
entropy generation. The heat exchanger's contribution exceeds the total external entropy generation by about $81 \%$ (see Fig. 7(b)) but falls short of the total internal entropy generation by about $14 \%$ (see Fig. 8(b)). A clear inference from these plots is that the major sub-domain contribution to entropy generation is from the heat exchanger. (Note: In Fig. 7(b) component "external" entropy generations are external to the particular component. Only the total external entropy generation is solely due to "external to the system" entropy generation).

Of the three cylinder's sub-domains, the outer cylinder's contribution to the entropy generation is most significant (external or internal). When taken as a whole, the cylinder's contribution to both external and internal entropy generations is minimal.

Table 4 illustrates entropy generation and availability loss results obtained for the "two-space" domain using Sage and CFD-ACE+. All CFD-ACE+ results, with the exception of the external entropy generation and availability energy loss results for the cylinder, are greater than corresponding Sage results. Calculation of the percentage differences between internal and external results of entropy and availability energy loss using CFD-ACE+ are based on the assumption that external results are more accurate since the calculation of the integral heat transfer rates are more dependable. With Sage, it does not seem to matter what the basis for calculation of the percentage differences is. Calculation of the percentage differences between Sage and CFD-ACE+ are based on the assumption that CFD$\mathrm{ACE}+$ results are more accurate since $\mathrm{CFD}-\mathrm{ACE}+$ is more suited to handle multi-dimensional flow situations.

With the exception of availability energy loss due to axial heat flow, results of losses due to flow friction and surface heat flow posted by Sage are greater in the heat exchanger than in the cylinder. Sage posts negligible flow frictional losses in the cylinder. As in the gas spring, the numerical errors reflected by the discrepancies between the internal and external availability energy losses indicate that Sage does a better job than CFD-ACE+ in satisfying the entropy generation accounting principle that the two methods of calculating for the entropy generation should give the same answer. This conclusion is also reflected in the results for the percentage differences between internal and external entropy generations (or availability energy losses) posted by Sage ( 7\%) and CFD-ACE+ $(\sim 12 \%)$.

The percentage differences between Sage and CFD-ACE total internal and external entropy generations for the twospace test rig are 41.8 and 51.8, respectively. From Table 3, the corresponding percentage differences for the gas spring are 0.8 and $0.5 \%$ respectively. The availability energy loss results show similar trend. Thus there is much better agreement between Sage and CFD-ACE in the entropy generation and availability energy loss calculations for the gas spring, than for the two-space rig. This may possibly be due to the inability of the Sage 1-D code to accurately account for temperature and velocity gradients caused by flow separations from walls where there are changes in flow area as for example, between the cylinder and the heat exchanger in the "two-space" test rig. Sage 1-D flow is assumed to immediately adjust to the wall boundaries through all geometrical changes in area and can only approximately account for the effect of flow separations, vortex formation, etc. where there are changes in flow area. It is noted that in the gas spring, Sage and CFD-ACE+ external calculations agree more than their internal calculations. The reverse is noted for the "two-space" model.

Figure 9 shows the distribution of entropy generation inside the two-space model. The impact of the entropy generation due to conductive heat transfer, fluid friction and mass transfer on the efficiency of the MIT models is quantified. Under the specified condition (201.7 RPM, $1.008 \mathrm{MPa}$., $\mathrm{T}_{\text {wall }}=294$ ), relatively higher losses are experienced in the heat exchanger. This is followed by losses in the outer cylinder and inner cylinder. Contributions from the mid-cylinder are very negligible. The heat exchanger's conductive heat transfer has the most impact on the "two-space" model efficiency followed by outer and inner cylinder conductive heat transfer. Contributions to the entropy generation due to viscous dissipation throughout the "two-space" domain and mid-cylinder's mass transfer and conductive heat transfer are very negligible. The relatively high losses in the heat exchanger support the extensive effort in the Stirling community to reduce the pressure drop in the regenerator which is a form of heat exchanger. In compact-heat-exchanger passages for example, improvements can be made in the constructive details of the channels (channel shape and aspect ratio, curvature of the return channels, etc.), the actual temperature differences between the cold and hot fluids, the surface finishing, and the type of materials used. 
Table 4. Gas Spring + Heat Exchanger Entropy Generation and Availability Energy Loss

\begin{tabular}{|c|c|c|c|c|c|c|c|c|}
\hline \multicolumn{9}{|c|}{ Gas Spring + Heat Exchanger } \\
\hline \multirow{4}{*}{ Sub-Domain } & \multicolumn{4}{|c|}{$\begin{array}{c}\text { Sage } \\
\left(\mathrm{T}_{\text {wall }}=300 \mathrm{~K}\right)\end{array}$} & \multicolumn{4}{|c|}{$\begin{array}{c}\text { CFD-ACE+: V2004 (Alpha version) } \\
\left(201.7 \mathrm{RPM}, 1.008 \mathrm{MPa} ., \mathrm{T}_{\text {wall }}=294 \mathrm{~K},\right) \\
(\text { Grid size }=147 \mathrm{x} 46, \# \mathrm{tspc}=480, \text { Opt. } \text { Cycle }=6)\end{array}$} \\
\hline & \multicolumn{2}{|c|}{ Internal } & \multicolumn{2}{|c|}{ External } & \multicolumn{2}{|c|}{ Internal } & \multicolumn{2}{|c|}{ External } \\
\hline & \multicolumn{8}{|c|}{ Entropy Generation (KW/K) } \\
\hline & \multicolumn{2}{|c|}{$\dot{\mathrm{S}}_{\mathrm{gen}, \mathrm{int}}=\frac{\mathrm{AEfric}+\mathrm{AEQw}+\mathrm{AEQx}}{\mathrm{T}_{\text {wall }}}$} & \multicolumn{2}{|c|}{$\dot{S}_{\text {gen an }}=\frac{\text { AEfric }+ \text { AEQw }+ \text { AEQx }-\mid \text { AEDiscr } \mid}{T_{\text {wall }}}$} & \multicolumn{2}{|c|}{$\dot{\mathrm{S}}_{\text {gen, int. }}=\dot{\mathrm{S}}_{\mathrm{gen}, \text { cond }}+\dot{\mathrm{S}}_{\mathrm{gen}, \text { visc }}$} & \multicolumn{2}{|c|}{$\dot{\mathrm{S}}_{\mathrm{gen,}, \mathrm{ext}}=-\oint_{\mathrm{dtds}} \frac{\mathrm{n} \cdot \mathrm{q}}{\mathrm{T}}$} \\
\hline Heat Exchanger & \multicolumn{2}{|c|}{0.00007069} & \multicolumn{2}{|c|}{0.00006535} & \multicolumn{2}{|c|}{0.000137} & \multicolumn{2}{|c|}{0.000327} \\
\hline Cylinder & \multicolumn{2}{|c|}{0.00002245} & \multicolumn{2}{|c|}{0.00002198} & \multicolumn{2}{|c|}{0.000023} & \multicolumn{2}{|c|}{-0.000146} \\
\hline Total & \multicolumn{2}{|c|}{0.00009314} & \multicolumn{2}{|c|}{0.00008733} & \multicolumn{2}{|c|}{0.000160} & \multicolumn{2}{|c|}{0.000181} \\
\hline Outer Cylinder & \multicolumn{2}{|c|}{-------- } & & & 0.0 & 155 & -0.00 & 108 \\
\hline Mid Cylinder & --- & $\begin{array}{l}--- \\
-1\end{array}$ & & & 0.0 & 014 & -0.00 & 003 \\
\hline Inner Cylinder & --- & --- & & & 0.0 & 062 & -0.00 & 035 \\
\hline & & & Availability & ergy Loss (K) & & & & \\
\hline AE Components & $\begin{array}{c}\text { Heat } \\
\text { Exchanger }\end{array}$ & Cylinder & $\begin{array}{c}\text { Heat } \\
\text { Exchanger }\end{array}$ & Cylinder & $\begin{array}{c}\text { Heat } \\
\text { Exchanger }\end{array}$ & Cylinder & $\begin{array}{c}\text { Heat } \\
\text { Exchanger }\end{array}$ & Cylinder \\
\hline AEfric & 0.00025860 & 0.00000000 & ---------- & ---------- & --------- & --------- & ---------- & --------- \\
\hline AEQw & 0.02089000 & 0.00659400 & --------- & ---------- & --------- & --------- & --------- & --------- \\
\hline AEQx & 0.00005789 & 0.00014010 & ---------- & --------- & --------- & --------- & --------- & --------- \\
\hline Sub-Domain & $\mathrm{AE}_{\text {int }}=\mathrm{AEfric}$ & AEQw + AEQx & $\mathrm{AE}_{\text {ext. }}=\mathrm{AEfric}+\mathrm{AE}$ & AEQx-|AEDiscr $\mid$ & $\mathrm{AE}_{\text {int }}=$ & $\dot{w}_{\text {wall }} \dot{\mathrm{S}}_{\mathrm{gen}, \text { int }}$ & $\mathrm{AE}_{\mathrm{ext}}=$ & $\Gamma_{\text {wall }} \dot{S}_{\text {gen, ext }}$ \\
\hline Heat Exchanger & 0.021 & 0649 & 0.01 & 549 & 0.0 & & 0.09 & 142 \\
\hline Cylinder & 0.006 & 3410 & 0.00 & 400 & 0.0 & & -0.04 & 2866 \\
\hline Total & 0.027 & 4059 & 0.02 & 949 & 0.0 & & 0.05 & 276 \\
\hline |AEDiscr| & & 0.0 & 17411 & & & 0.00 & & \\
\hline Outer Cylinder & --- & --- & & & 0.0 & & -0.03 & 859 \\
\hline Mid Cylinder & --- & --- & & & 0.0 & & -0.00 & 809 \\
\hline Inner Cylinder & --- & $\begin{array}{l}--- \\
-1\end{array}$ & & & 0.0 & & -0.01 & 198 \\
\hline Sub-Domain & $1 \% \mathrm{I}$ & fference| bety & en Internal an & xternal Entro & Generatio & r Availabi & Energy Lo & \\
\hline Heat Exchanger & & & .0 & & & 58 & & \\
\hline Cylinder & & & .0 & & & 11 & & \\
\hline Total & & & .0 & & & 12 & & \\
\hline Outer Cylinder & & & $\begin{array}{l}---- \\
-\cdots\end{array}$ & & & 11 & & \\
\hline Mid Cylinder & & & $-{ }_{-1--}$ & & & 14 & & \\
\hline Inner Cylinder & & & ---- & & & 11 & & \\
\hline & & & \% Difference| & veen Sage an & V2004 (Alph & ersion) & & \\
\hline & & & rnal & & & Ext & & \\
\hline & Entropy & Feneration & & & Entropy ( & eration & AE I & \\
\hline Heat Exchanger & & .4 & & & 80 & & 79 & \\
\hline Cylinder & & 4 & & & 11 & & 115 & \\
\hline Total & & .8 & & & & & 50 & \\
\hline
\end{tabular}




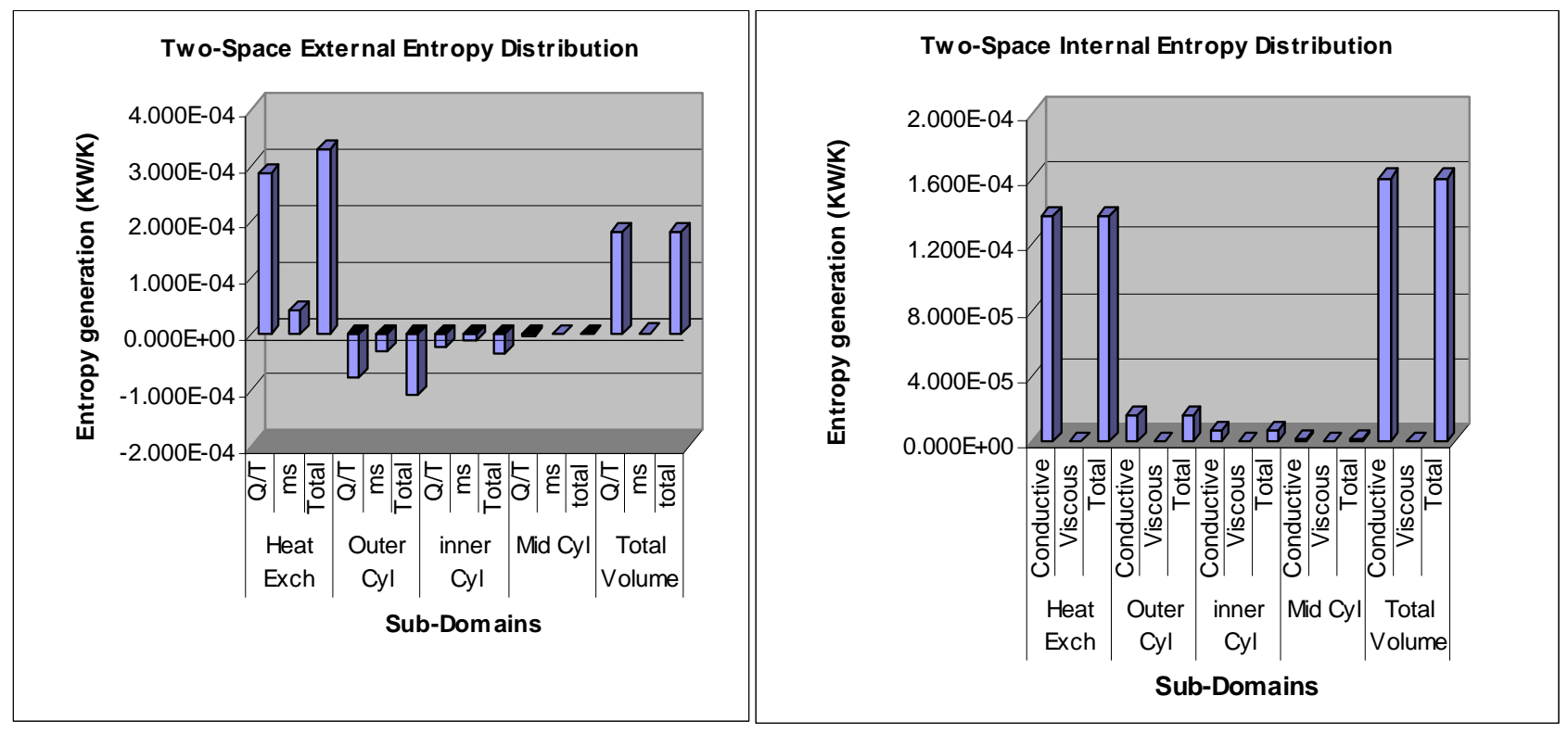

Figures 9. External and Internal Entropy Distribution in the "Two-Space" Model

(201.7 RPM, 1.008 MPa., $T_{\text {wall }}=294 \mathrm{~K} ;$ Grid size $=147$ x 51，\#tspc $=480$, at Opt. Cycle $\left.=6\right)$.

\section{Concluding Remarks}

A discussion of the computer models of the MIT gas spring and "two-space" test rigs, post-processing of the numerical simulation results and entropy generation/availability energy loss analysis results for the models have been provided. Sage and CFD-ACE+ simulation results of temperature, velocity, pressure and surface heat transfer were post-processed for major thermodynamic losses via entropy generation. An important and primary objective of this study is the development and application of a thermodynamic loss post-processor to characterize the major thermodynamic losses inside the two MIT test rigs. The experience gained from thermodynamic loss analysis of simple systems such as the MIT test rigs are often useful for application to more complex systems like the Stirling engine. Thus this study is motivated by the future need to incorporate a thermodynamic loss post-processor in Stirling engine analysis codes in order to facilitate Stirling engine performance optimization.

The following conclusions can be drawn from the results of this study which sought to characterize the irreversibilities related to heat transfer, mass flow and viscous friction occurring in the MIT test rigs via entropy generation:

(1) In both the "single-space" and "two-space" models the two methods of accounting for the entropy generation (external and internal) appear insensitive to the number of cycles of piston motion beyond the third cycle.

(2) In both test rigs, CFD-ACE+ does not satisfy the accounting principle as well as Sage. In the "single-space" model the two methods yielded essentially the same result as they should in principle. Clear differences in results are noted for the "two-space" model.

(3) With few exceptions, all CFD-ACE+ results of entropy generation and availability energy loss are less than corresponding Sage results for the "single-space" model but greater for the "two-space" model.

(4) Sage and CFD-ACE entropy generation and availability energy loss calculations are in better agreement for the "single-space" model than for the "two-space" model. This may possibly be due to the fact that CFD-ACE+ is more suited to handle multi-dimensional flow situations.

(5) It is noted that in the gas spring, Sage and CFD-ACE+ external calculations agree more than their internal calculations. The reverse is noted for the "two-space" model.

(6) Sage results for the gas spring show that the primary contribution to the total availability energy loss is the energy loss to surface heat flow. 
(7) In the "two-space" model, the heat exchanger provides the major sub-domain contribution to the entropy generation. Thus the heat exchanger heat transfer has the most impact on the "two-space" model efficiency followed by outer and inner cylinder heat transfer. Viscous dissipation throughout the entire "two-space" domain and mid-cylinder mass transfer and conductive heat transfer contribute minimally to the model's efficiency.

Typically neglected and often viewed as superfluous, the second law of thermodynamics remains an esoteric and mysterious subject ${ }^{17}$ particularly in computational analysis of thermo-fluid systems. When properly applied, the second law of thermodynamics has proven to be a very powerful tool in the optimization of complex thermodynamic systems. Loss analysis using entropy-generation rates due to heat and fluid flow is a relatively new technique for assessing component performance. It offers a deep insight into the flow phenomena, allows a more exact calculation of losses than is possible with traditional means involving the application of loss correlations and provides an effective tool for improving performance. Designers will know the cumulative amount of all losses computed locally in the flow domain. Entropy generation maps can be produced, and designers can use them by scanning them to detect critical areas (locations in which entropy generation is higher than its integral average value over the entire flow field). By considering the local values of entropy generation rates due to thermal and viscous dissipation, designers can generate a thermodynamically better design by simply trying to avoid these critical areas or recomputing them after a design modification has been introduced to assess local and global effects of the design change.

Our understanding of loss mechanisms is however far from complete. Although numerical predictions are valuable in predicting the heat transfer and flow structure, there are difficulties in predicting the loss accurately. This is due to errors in predicting the boundary layers, transition as well as due to false entropy generation due to numerical dissipation. This work provides a point of reference for incorporation of loss post-processors into Stirling engine numerical codes. The incorporation of a loss post-processor in Stirling engine numerical codes, it is believed, will facilitate the optimization of Stirling engine performance. 


\section{References}

${ }^{1}$ Bejan, A., Second-law analysis in heat transfer and thermal design, Adv. Heat Transfer 15 (1982) 1-58.

${ }^{2}$ Bejan, A. A study of entropy generation in fundamental convective heat transfer, J. Heat Transfer 101 (1979) 718725 .

${ }^{3}$ Bejan, A., Entropy Generation Minimization, CRC, Boca Raton, NY, 1996.

${ }^{4}$ Bejan, A., Advanced Engineering Thermodynamics, $2^{\text {nd }}$. ed., John Wiley and Sons, Inc., 1997.

${ }^{5}$ Cengel, Y. A. and Boles, M. A., Thermodynamics, an Engineering Approach, $5^{\text {th }}$. ed., The McGraw-Hill Companies, Inc., 2006.

${ }^{6}$ Connelly, L. and Koshland, C. P. (1997). "Two aspects of consumption: using an exergy-based measure of degradation to advance the theory and implementation of industrial ecology", Resource Conservation Recycling, $19,199-217$.

${ }^{7}$ Cornelissen, R. L. and Hirs, G. G. (1998). "Exergetic life cycle analysis of components in a system", in Thermodynamics and the Optimization of Complex Energy Systems, NATO Advanced Study Institute, Neptun, Romania, pp. 411-422.

${ }^{8}$ Chafe, J.N., "A Study of Gas Spring Heat Transfer in Reciprocating Cryogenic Machinery," Ph.D. Thesis, Dept. of Mech. Eng., Massachusetts Institute of Technology, Cambridge, MA, 1988.

${ }^{9}$ Creyts, J. C. and Carey, V. P. (1997). "Use of extended exergy analysis as a tool for assessment of the environmental impact of industrial processes", Proc. ASME Advanced Energy Systems Division, Part 2, AESVol. 37, M.L. Ramalingam, J. L. Lage, V. C. Mei and J. N. Chapman (Eds.), American Society of Mechanical Engineers, New York, pp. 129-137.

${ }^{10}$ Currie, T.C. and Carscallen, W.E. Simulation of trailing edge vortex shedding in a transonic turbine cascade. ASME Paper No. 96-GT-483, 1996.

${ }^{11}$ Denton, J.D., 1993. Loss mechanisms in turbomachines. ASME Paper No. 93-GT-435.

${ }^{12}$ Drost, M. K., Zaworski, J.R., A review of second law analysis techniques applicable to basic thermal science research, ASME, AES 4 (1988) 7-12.

${ }^{13}$ Ebiana, A.B., Savadekar, R.T, Vallury, A., "2 ${ }^{\text {nd }}$ Law Analysis of Sage and CFD-ACE+ Models of MIT Gas Spring and "Two-Space" Test Rigs", Proceedings of $2^{\text {nd }}$. International Energy Conversion Engineering Conference. Aug 16-Aug 19, 2004, Providence, Rhode Island.

${ }^{14}$ El-Sayed, Y. M. and Gaggioli, R. A. (1989). "A critical review of second law costing methods. Parts I and II", Trans. ASME: J. Energy Resour. Technol., 111, 1-15.

${ }^{15}$ Faulkner, H.B., "An Investigation of Instantaneous Heat Transfer During Compression and Expansion in Reciprocating Gas Handling Equipment," Ph.D. Thesis, Dept. of Mech. Eng., Massachusetts Institute of Technology, Cambridge, MA, 1983.

${ }^{16}$ Gedeon, D., Sage User's Guide, $3^{\text {rd }}$.ed., (Gedeon Associates, 16922 South Canaan Road, Athens, OH 45701), 1999.

${ }^{17}$ Grad, H., "The Many Faces of Entropy". Communications on Pure and Applied Mathematics, vol. XIV, pp. 323354, 1961.

${ }^{18}$ Hafele, W. (Ed.). Energy in a Finite World: A Global Systems Analysis, Ballinger, Toronto.

${ }^{19}$ Hofman, K.A., Chiang, S.T., Computational Fluid Dynamics for Engineers Volume II, Engineering Education System, 1993, pp. 15.

${ }^{20}$ Kornhauser, Alan A. "Gas-Wall Heat Transfer During Compression and Expansion”, Ph.D. Thesis, Dept. of Mech. Eng., Massachusetts Institute of Technology, Cambridge, MA, 1989.

${ }^{21}$ Lee, K.P. and Smith, J.L. Jr., "Influence of Cyclic Wall-to-Gas Heat Transfer in Cylinder of the Valved Hot-Gas Engine", Proceedings of the $13^{\text {th }}$. Intersociety Energy Conversion Engineering Conference, Paper No 789195, 1978. 
${ }^{22}$ Merle C. Potter and John F. Foss, Fluid Mechanics, John Wiley \& Sons, Inc., 1975.

${ }^{23}$ Narusawa, U., The second-law analysis of mixed convection in rectangular ducts, Heat Mass Transfer 37 (2001) 197-203.

${ }^{24}$ Paoletti, S., Rispoli, F., Sciubba, E., Calculation of exergetic losses in compact heat exchanger passages, ASME AES 10 (1989) 21-29.

${ }^{25}$ Recktendwald, G. W., "A Study of Heat Transfer between the Walls and Gas Inside the Cylinder of a Reciprocating Compressor,” University of Minnesota Ph.D. Thesis, 1989.

${ }^{26}$ Rosen, M. A. (1991). "An investigation of the relation between capital costs and selected thermodynamic losses", in Second Law Analysis - Industrial and Environmental Applications, AES-Vol. 25/HTD-Vol. 191, G. M. Reistad et al. (Eds), American Society of Mechanical Engineers, New York, pp. 55-62.

${ }^{27}$ Rosen, M. A. and Dincer, I. (1997). “On exergy and environmental impact”, Int. J. Energy Res., 21, 643-654.

${ }^{28}$ Sahin, A. Z., Second law analysis of laminar viscous flow through a duct subjected to constant wall temperatures, J. Heat Transfer 120 (1980) 76-83.

${ }^{29}$ Tannehill, J.C., Anderson, D.A. and Pletcher, R.H., Computational Fluid Mechanics and Heat Transfer, Taylor \& Francis, $2^{\text {nd. }}$ ed., Hemisphere Publishing Corporation, 1984.

${ }^{30}$ Terrence W. Simon and Jorge R. Seume, “A Survey of Oscillating Flow in Stirling Engine Heat Exchangers" NASA Contractor Report 182108, Mar. 1988.

${ }^{31}$ Tew, Roy C. Jr., "Two-Dimensional Compressible Non-Acoustic Modeling of Stirling Machine Type Components", Doctor of Engineering Thesis, Dept. of Mech. Eng., Cleveland State University, Cleveland, OH, 2000 .

${ }^{32}$ Tew, R.C., et al, "Overview 2004 of NASA-Stirling Convertor CFD Model Development and Regenerator R\&D Efforts", in proceedings of Space Technology and Applications International Forum (STAIF 2005), Albuquerque, NM February 2005.

${ }^{33}$ Thieme, L.G. and Schreiber, J.G., NASA GRC Stirling Technology Overview, " Proceedings of the Space Technology Applications international Forum (STAIF-2003), Albuquerque, NM, edited by M.S. El-Genk, American Institute of Physics, Melville, NY, 2003, AIP CP-654, pp. 613-620, also as NASA/TM--2003-212454, 2003.

${ }^{34}$ Thompson, K.W., Lecture Series in Computational Fluid Dynamics, NASA TM 100010, August 1987.

${ }^{35}$ Torres, C., Serra, L., Valero, A. and Lozano, M. A. (1996). "The productive structure and thermoeconomic theories of system optimization", in Proc. ASME Advanced Energy Systems Division, AES-Vol. 36, American Society of Mechanical Engineers, New York, pp. 429-436.

${ }^{36}$ Tsatsaronis, G. (1998). "Design optimization using exergoeconomics", in Thermodynamics and the Optimization of Complex Energy Systems, NATO Advanced Study Institute, Neptun, Romania, pp. 394-410.

${ }^{37}$ White, Frank M. Fluid Mechanics, $4^{\text {th }}$. ed., The McGraw-Hill Companies, Inc., 1999.

${ }^{38}$ Zhang, M. and Reistad, G. M. (1998). "Analysis of energy conversion systems, including material and global warming aspects”, Int. J. Heating, Ventilating, Air-Conditioning Refrigerating Res., 1(1), 45-65. 
Public reporting burden for this collection of information is estimated to average 1 hour per response, including the time for reviewing instructions, searching existing data sources, gathering and maintaining the data needed, and completing and reviewing the collection of information. Send comments regarding this burden estimate or any other aspect of this collection of information, including suggestions for reducing this burden, to Washington Headquarters Services, Directorate for Information Operations and Reports, 1215 Jefferson Davis Highway, Suite 1204, Arlington, VA 22202-4302, and to the Office of Management and Budget, Paperwork Reduction Project (0704-0188), Washington, DC 20503.

\begin{tabular}{|l|l|l|}
\hline 1. AGENCY USE ONLY (Leave blank) & $\begin{array}{c}\text { 2. REPORT DATE } \\
\text { June } 2006\end{array}$ & $\begin{array}{c}\text { 3. REPORT TYPE AND DATES COVERED } \\
\text { Final Contractor Report }\end{array}$ \\
\hline
\end{tabular}

4. TITLE AND SUBTITLE 5. FUNDING NUMBERS

Entropy Generation/Availability Energy Loss Analysis Inside MIT Gas Spring and "Two-Space" Test Rigs

6. AUTHOR(S)

Asuquo B. Ebiana, Rupesh T. Savadekar, and Kaushal V. Patel

WBS-138494.04.01.01

NAG3-2819

7. PERFORMING ORGANIZATION NAME(S) AND ADDRESS(ES)

8. PERFORMING ORGANIZATION REPORT NUMBER

Cleveland State University

2121 Euclid Avenue

E-15575

Cleveland, Ohio 44115

9. SPONSORING/MONITORING AGENCY NAME(S) AND ADDRESS(ES)

National Aeronautics and Space Administration

Washington, DC 20546-0001

10. SPONSORING/MONITORING AGENCY REPORT NUMBER

NASA CR - 2006-214339

AIAA-2005-5675

\section{SUPPLEMENTARY NOTES}

Prepared for the Third International Energy Conversion Engineering Conference (IECEC) sponsored by the American Institute of Aeronautics and Astronautics, August 15-18, 2005, San Francisco, California. Project manager, Roy Tew, Power and Electric Propulsion Division, NASA Glenn Research Center, organization code RPT, 216-433-8471.

12a. DISTRIBUTION/AVAILABILITY STATEMENT 12b. DISTRIBUTION CODE

Unclassified - Unlimited

Subject Category: 20

Available electronically at http://gltrs.grc.nasa.gov

This publication is available from the NASA Center for AeroSpace Information, 301-621-0390.

13. ABSTRACT (Maximum 200 words)

The results of the entropy generation and availability energy loss analysis under conditions of oscillating pressure and oscillating helium gas flow in two Massachusetts Institute of Technology (MIT) test rigs - piston-cylinder and piston-cylinder-heat exchanger-are presented. Two solution domains, the gas spring ("single-space") in the piston-cylinder test rig and the gas spring + heat exchanger ("two-space") in the piston-cylinder-heat exchanger test rig are of interest. Sage and CFD-ACE+ commercial numerical codes are used to obtain 1-D and 2-D computer models, respectively, of each of the two solution domains and to simulate the oscillating gas flow and heat transfer effects in these domains. Second law analysis is used to characterize the entropy generation and availability energy losses inside the two solution domains. Internal and external entropy generation and availability energy loss results predicted by Sage and CFD-ACE+ are compared. Thermodynamic loss analysis of simple systems such as the MIT test rigs are often useful to understand some important features of complex pattern forming processes in more complex systems like the Stirling engine. This study is aimed at improving numerical codes for the prediction of thermodynamic losses via the development of a loss post-processor. The incorporation of loss post-processors in Stirling engine numerical codes will facilitate Stirling engine performance optimization. Loss analysis using entropy-generation rates due to heat and fluid flow is a relatively new technique for assessing component performance. It offers a deep insight into the flow phenomena, allows a more exact calculation of losses than is possible with traditional means involving the application of loss correlations and provides an effective tool for improving component and overall system performance.

14. SUBJECT TERMS

Stirling engines; Second law analysis; Entropy generation; Computerized simulation; Unsteady flow; Convective heat transfer

\begin{tabular}{|c|c|c|}
\hline $\begin{array}{c}\text { 17. SECURITY CLASSIFICATION } \\
\text { OF REPORT } \\
\text { Unclassified }\end{array}$ & $\begin{array}{c}\text { 18. SECURITY CLASSIFICATION } \\
\text { OF THIS PAGE } \\
\text { Unclassified }\end{array}$ & $\begin{array}{c}\text { 19. SECURITY CLASSIFICATION } \\
\text { OF ABSTRACT } \\
\text { Unclassified }\end{array}$ \\
\hline
\end{tabular}

15. NUMBER OF PAGES

30

16. PRICE CODE

20. LIMITATION OF ABSTRACT

Standard Form 298 (Rev. 2-89)

Prescribed by ANSI Std. Z39-18 298-102 

